\title{
ReVISIÓN TAXONÓMICA DEL GÉNERO VibuRnUM (Adoxaceae) para México
}

\author{
José Ángel Villarreal-Quintanilla ${ }^{1,3}$ y A. Eduardo Estrada-Castillón ${ }^{2}$ \\ 'Departamento de Botánica, Universidad Autónoma Agraria Antonio Narro, Saltillo, Coahuila, México. \\ ${ }^{2}$ Facultad de Ciencias Forestales, Universidad Autónoma de Nuevo León, Linares, Nuevo León, México. \\ ${ }^{3}$ Autor para correspondencia: javillarreal00@hotmail.com
}

\begin{abstract}
Resumen: Se realizó una revisión taxonómica del género Viburnum para México, mediante el estudio de ejemplares de herbarios nacionales y del extranjero. En México se presentan 20 taxones que son agrupados en 17 especies y tres taxones infraespecíficos. La distribución del género es principalmente en el centro y sur del país, extendiéndose por el noreste hasta el norte de Coahuila. Oaxaca y Chiapas son los estados con el mayor número de especies. Las siguientes combinaciones nomenclaturales se presentan como nuevas: Viburnum acutifolium Benth. var. blandum (C.V.Morton) Villarreal \& A.E.Estrada, V. acutifolium Benth. var. lautum (C.V.Morton) Villarreal \& A.E.Estrada y V. acutifolium Benth. var. microphyllum (Oerst.) Villarreal \& A.E.Estrada. Siete subsecciones nuevas se proponen en la clasificación del género para México: Acutifolia, Discolora, Elata, Hartwegiana, Microcarpa, Prunifolia y Rafinesquiana. Se incluye una clave para la determinación de taxones, descripciones y mapas de distribución.
\end{abstract}

Palabras clave: Adoxaceae, Caprifoliaceae, taxonomía.

\begin{abstract}
A taxonomic revision of the genus Viburnum in México was made. Specimens in Mexican and foreign herbaria were examined. In Mexico there are 20 taxa, 17 species and three varieties. They are mainly distributed in the central and southern areas, some of them reaching the northeastern region. Oaxaca and Chiapas are the states with the largest number of taxa. The following nomenclatural combinations are presented as new: Viburnum acutifolium Benth. var. blandum (C.V.Morton) Villarreal \& A.E.Estrada, V. acutifolium Benth. var. lautum (C.V.Morton) Villarreal \& A.E.Estrada and V. acutifolium Benth. var. microphyllum (Oerst.) Villarreal \& A.E.Estrada. Seven new subsections are proposed: Acutifolia, Discolora, Elata, Hartwegiana, Microcarpa, Prunifolia and Rafinesquiana. A key to identify the taxa, descriptions and maps are included.
\end{abstract}

Key words: Adoxaceae, Caprifoliaceae, taxonomy.

$\mathbf{E}$ l género Viburnum, que originalmente incluía ocho especies, fue propuesto por Linneo (1753). Posteriormente, Bentham $(1840,1841)$ publicó cinco para México y Guatemala; Oersted (1861), propuso la segregación en cinco géneros de las especies conocidas hasta esa fecha. Las correspondientes para México fueron todas ubicadas en Oreinotinus Oerst., excepto $V$. elatum Benth., que la conservó en el género Viburnum, posteriormente fueron transferidas a Viburnum por Hemsley (1881). En la actualidad, comprende unas 175 especies de arbustos y árboles pequeños que se distribuyen en el Hemisferio Norte, Asia y Sudamérica.

Originalmente, este género es considerado como parte de la familia Caprifoliaceae Juss. (sensu lato) propuesta por A. L. de Jussieu en 1789. Permaneció como miembro de la tribu Sambuceae hasta 1891 en que Fritsch lo separó junto con Triosteum en la tribu Viburneae. Más tarde, es segregado por Rafinesque como miembro único en Viburnaceae Raf. (1820), reconocido así en la clasificación de Angiospermas de Dahlgren (1980), y posteriormente en 1839, es incluido junto con otros seis géneros en Adoxaceae E.Mey. Actualmente, las evidencias morfológicas y moleculares lo relacionan con Sambucus y Adoxa (Donoghue et al., 1992).

El género Viburnum se reconoce como monofilético con una diversificación inicial en el este de Asia; además, el este de Norteamérica y las regiones montañosas de México, Centroamérica y norte de Sudamérica son también contemplados como centros de alta diversidad (Donoghue, 1983). Las especies americanas, en su mayoría parecen haberse derivado de clados asiáticos. De esta forma, el género presenta un patrón clásico de distribución disyunta entre el Viejo y 
el Nuevo Mundo. Las especies de América Latina parecen estar relacionadas directamente con las del este de Estados Unidos (Winkworth y Donoghue, 2005).

Para México, Standley (1926) registró 15 especies. Viburnum microcarpum Schltdl. \& Cham., fue la primera en describirse para México en 1830; posteriormente Morton (1933) propuso seis nuevas y reconoció solo 20 para el país. Más tarde se publicaron otros taxones como nuevos (Gibson, 1973; Lundell, 1939a, b, 1966; Matuda 1956), acumulándose así un poco más de 50 nombres para las plantas mexicanas. No obstante, cerca de la mitad de estos nombres han sido reducidos a sinonimia o forman parte de combinaciones nomenclaturales en el presente trabajo. Más recientemente, Donoghue (1982) realizó un estudio sistemático del género, donde sugirió combinaciones nuevas y el arreglo en "complejos de especies" para América Latina, sin llegar a publicar formalmente ninguna de ellas. Algunas revisiones para floras locales fueron presentadas por Arreguín (2001) y Villarreal (2000, 2003, 2012).

La taxonomía del grupo se basa principalmente en caracteres vegetativos, como la forma de la hoja y sus dimensiones, el margen, el ápice, la nervación, el desarrollo de la inflorescencia y en especial, resulta muy importante el tipo de indumento. Menor variación se presenta en la morfología de la flor, el fruto y el pireno en las especies estudiadas. Aunque la mayoría de los especímenes de herbario presentan estructuras florales o frutos, es frecuente que se le confunda con representantes de otros géneros como Cornus (Cornaceae), con el cual comparte el tipo de hoja e inflorescencia.

Las clasificaciones subgenéricas para el grupo de taxones mexicanos incluyen la de Morton (1933), que propone diez secciones para agrupar las especies mexicanas y centroamericanas. Donoghue (1982) las ubica en varios complejos de especies, y posteriormente Winkworth y Donoghue (2005), en un estudio de filogenia molecular, reconocen diez secciones para el género y encuentran que no todas se comportan como monofiléticas. Tomando en cuenta el arreglo tradicional, como el presentado por Hara (1983), se consideraron las tres secciones (Lentago, Odontotinus y Oreinotinus) que incluyen especies mexicanas, y se propone una clasificación en subsecciones como una forma de ayudar a entender mejor la taxonomía de los miembros del género en el área.

Con el objetivo de conocer los taxones que conforman a Viburnum para México, se realizó el presente trabajo consistente en un tratamiento taxonómico del género, donde se revisó la nomenclatura, se delimitaron especies y variedades, y éstas se clasificaron en secciones y subsecciones con base en un análisis de similitud morfológica.

\section{Materiales y métodos}

Se llevó a cabo la revisión del material depositado en los herbarios ANSM, ENCB, MEXU, IEB, XAL y parcialmente el de NY (ver Thiers para los acrónimos). Se consultó la base de datos de la colección del herbario de la Universidad de Texas, en Austin (TEX), y la de Trópicos del herbario del Missouri Botanical Garden (MO); además, se hizo un examen bibliográfico de trabajos acerca de Viburnum y artículos donde se describen especies nuevas para México. No se tomaron en consideración las muestras de plantas introducidas y cultivadas como ornamentales.

Se realizó un estudio del material y la información disponible, se revisó la taxonomía del género, se consideraron los caracteres morfológicos tradicionalmente usados para la identificación de los taxones, elaborándose con ellos descripciones completas. Los datos de nombres comunes, usos, tipos de vegetación y altitud se tomaron de los ejemplares consultados. Se realizó una clasificación infragenérica para secciones y subsecciones y una clave para los taxones mexicanos. Se crearon mapas de distribución, denotando la presencia por estados. Para la cita de nombres de autores se siguió a Villaseñor et al. (2008). Dado que para algunas especies se cuenta con un número elevado de ejemplares consultados, sólo se citan tres a cinco ejemplares por estado, con excepción de aquellas especies con un número reducido de muestras conocidas.

Con el propósito de observar la agrupación de las especies y sugerir una clasificación infragenérica, se realizó un análisis de similitud con base en características morfológicas de interés taxonómico. Se revisaron la mayoría de las especies conocidas para Norte y Centroamérica, excluyendo los complejos de Viburnum acerifolium y $V$. dentatum, que no presentan distribución en México. Se preparó una matriz de datos en Microsoft Excel que incluyó 29 caracteres (filas) y 20 Operational Taxonomic Units (OTUs), representadas por las especies y variedades (columnas). La lista de caracteres se presenta en el Apéndice 2 y la matriz de datos está disponible bajo solicitud con el primer autor. Los datos fueron analizados por la técnica de agrupamiento con la ayuda del programa NTSYSpc Version 2.0 (Rohlf, 1998). El coeficiente de similitud empleado fue el de Jaccard y el método de agrupamiento fue UPGMA para la obtención del fenograma.

\section{Resultados}

Se reconocen 20 taxones de Viburnum para México, correspondientes a 17 especies, una de ellas con tres variedades adicionales, diez son endémicas de México. El género se distribuye en las regiones montañosas del noreste, centro y sur del país, localizándose en 20 estados, Oaxaca con el mayor número de representantes (12), seguido de Chiapas (9), Guerrero (6), Hidalgo y Veracruz (5), Jalisco, Michoacán y Puebla (4), y otros estados con menor número de especies. Viburnum elatum es la especie más ampliamente distribuida (14 estados), mientras que V. acutifolium var. acutifolium, $V$. membranaceum y V. sulcatum sólo se les conoce de Oaxaca, V. acutifolium var. blandum y V. acutifolium var. lautum de 
Chiapas, y a V. rufidulum del norte de Coahuila. Tres combinaciones nomenclaturales no previamente publicadas son incluidas.

El estudio morfológico distingue seis grupos de especies. El primero, que en el fenograma se separa del resto, representa a la secciónes Odontotinus y Lentago (Figura 1), las características que las definen y sus componentes se mencionan más adelante. El primer grupo con tres especies, conforma la subsección Rafinesquiana, relacionada morfológicamente con los elementos de Lentago, donde están las subsecciones Elata, integrada por una sola especie y, Prunifolia por cuatro. Un segundo grupo corresponde a la seccion

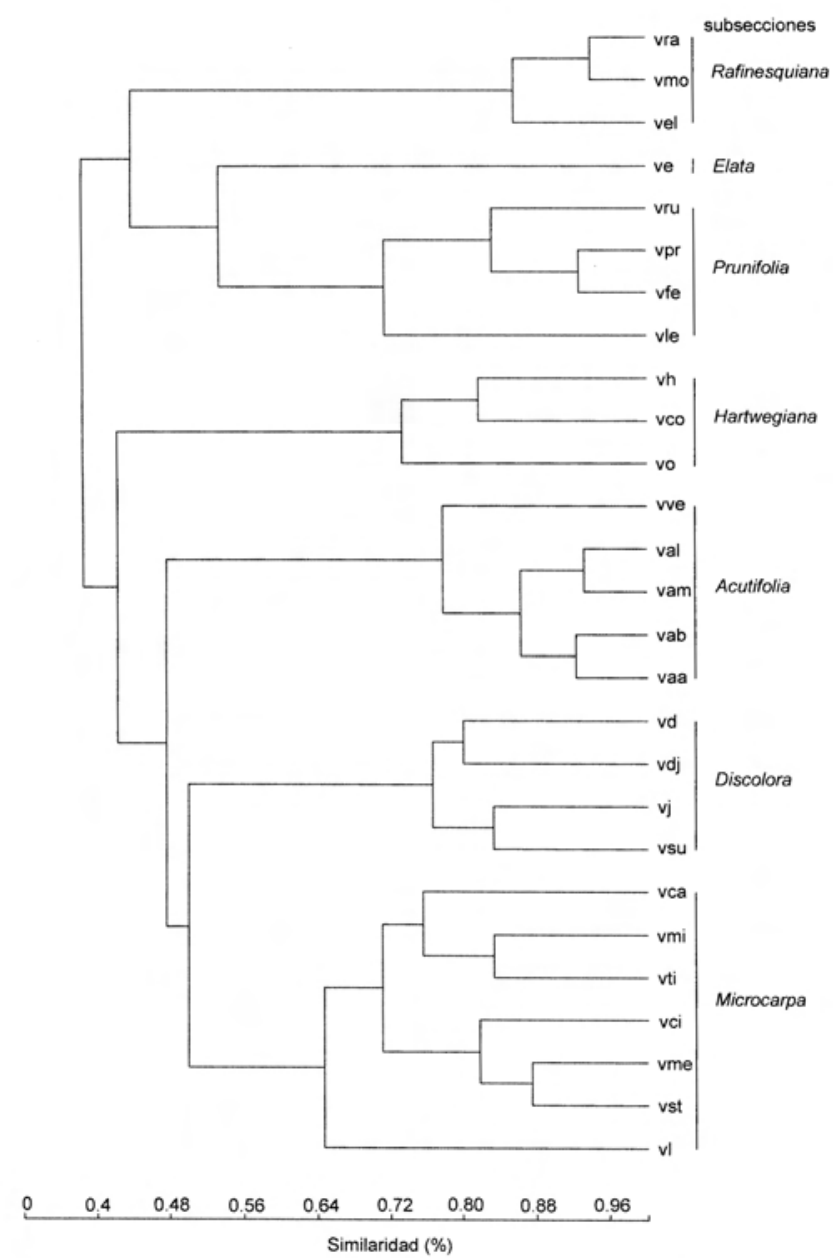

Figura 1. Dendrograma que muestra la agrupación de especies de Viburnum en México y otras relacionadas por similitud morfológica. Valor cofenético, $\mathrm{r}=0.85$. vaa=Viburnum acutifolium var. acutifolium, $\mathrm{vab}=V$. acutifolium var. blandum, val $=$ V. acutifolium var. lautum, vam $=V$. acutifolium var. microphyllum, vca $=V$. caudatum, $\mathrm{vci}=V$. ciliatum, $\mathrm{vco}=V$. costaricanum, $\mathrm{vd}=V$. discolor, $\mathrm{vdj}=V$. disjunctum, ve $=V$. elatum, vel $=V$. ellipticum,, $\mathrm{vfe}=V . f e-$ rrugineum, $\mathrm{vh}=V$. hartwegii, $\mathrm{vj}=V$. jucundum, $\mathrm{vl}=V$. loeseneri, $\mathrm{vle}=V$. lentago, vme $=V$. membranaceum, $\mathrm{vmi}=V$. microcarpum, $\mathrm{vmo}=V$. molle, $\mathrm{vo}=V$. obtusum, $\mathrm{vpr}=V$. prunifolium, $\mathrm{vra}=V$. rafinesquianum, $\mathrm{vru}=V$. rufidulum, $\mathrm{vst}=V$. stenocalyx, $\mathrm{vsu}=V$. sulcatum, vti $=V$. tiliifolium, vve $=V$. venustum .
Oreinotinus. En ella el primer conjunto en separarse es el denominado Hartwegiana con tres especies, el siguiente es Acutifolia formado por Viburnum venustum y V. acutifolium y sus variedades. Los restantes con la mayor similitud morfológica son Discolora con cuatro especies y Microcarpa con siete. La delimitación de los grupos mencionados y su arreglo se presenta en la clasificación infragenérica.

Viburnum L., Sp. Pl. 267. 1753.

Oreinotinus Oerst., Vidensk. Meddel. Dansk Naturhist. Foren. Kjöbenhavn 1860: 281. 1861.

Árboles o arbustos deciduos o siempre verdes; tallos erectos o postrados; lenticelas notorias, pubescencia de escasa a densa, de pelos simples, estrellados y glandulares, o glabros, yemas protegidas por 2-4 pares de escamas imbricadas; ramas opuestas. Hojas opuestas, en ocasiones verticiladas, simples, pecioladas, estípulas caedizas, o persistentes, adnadas al pecíolo; limbo con margen entero a irregularmente dentado, raramente lobado, nervación pinnada o palmada, glabros a pubescentes, membranáceos o subcoriáceos. Inflorescencias corimbosas, umbeliformes, bracteadas, dos o más veces compuestas, o paniculadas, usualmente terminales. Flores pequeñas, fragantes, pentámeras, actinomorfas y perfectas, aunque las marginales frecuentemente zigomorfas y estériles; cáliz con un tubo glandular, pubescente o glabro y 5 lóbulos pequeños, persistentes en el fruto; corola rotada a campanulada, blanca o rosada, prefloración imbricada, lóbulos extendidos; estambres 5, exsertos, filamentos atenuados hacia el ápice, insertos en la base del tubo de la corola, glabros, anteras cerca de $1 \mathrm{~mm}$ de largo, dorsifijas, introrsas, de dehiscencia longitudinal, amarillas a púrpuras; pistilo de 1-3 carpelos, ovario ínfero, unilocular, uniovular, adnado al tubo del cáliz, estilo corto y grueso o ausente, glabro o pubescente, estigma 3-lobado, lóbulos muy cortos. Fruto una drupa, globosa a elipsoidal, generalmente algo aplanada, en ocasiones con un surco central formado por la intrusión del exocarpo, glabra o con pelos glandulares esparcidos, roja a negra; pireno elipsoidal, ligeramente aplanado, usualmente con uno a varios surcos longitudinales, semilla una.

Género con unas 175 especies de zonas templadas y montañosas intertropicales, la mayoría en el Hemisferio Norte, extendiéndose en Asia hasta Java y en América hasta la región andina de Sudamérica. Algunas especies son cultivadas con fines ornamentales (Viburnum tinus y V. pubescens han sido registradas en México).

\section{Clasificación infragenérica}

La clasificación infragenérica para los taxones mexicanos está basada en el arreglo tradicionalmente reconocido para secciones (p.ej. Hara, 1983), y la que aquí se propone para subsecciones es de acuerdo al agrupamiento que se presenta en el estudio de similitud morfológica (Figura 1). 
Sección Odontotinus Rehder, Trees \& Shrubs 2(2): 113. 1908.

Plantas con hojas notoriamente dentadas; cimas pedunculadas; estilos glabros; frutos aplanados y sulcados. Unas 37 especies distribuidas en Asia y Norteamérica.

Subsección Rafinesquiana Villarreal \& A.E.Estrada, subsec. nov. Especie tipo: Viburnum rafinesquianum Schult.

Secc. Stipulata C.V.Morton, Contr. U.S. Nat. Herb. 26: 342. 1933.

Plants with leaves coarsely dentate, usually stipulated; pyrene and fruit flattened and sulcate.

Viburnum rafinesquianum consta de dos variedades presentes en Canadá y los Estados Unidos, la variedad affine extiende su distribución al noreste de México.

Viburnum ellipticum Hook. y V. molle Michx., localizadas también en Norteamérica y muy relacionadas morfológicamente con la especie anterior, son ubicadas en esta subsección.

Sección Lentago DC., Prodr. 4: 324. 1830.

Plantas con hojas enteras a aserradas; cimas sésiles o con pedicelos cortos; radios primarios 4(-5); estilos glabros; pirenos aplanados, sin surcos. Cinco especies del este de Norteamérica; Viburnum elatum, V. ferrugineum, V. lentago, V. prunifolium y V. rufidulum.

Subsección Elata Villarreal \& A.E.Estrada, subsec. nov. Especie tipo: Viburnum elatum Benth.

Secc. Sessilia C.V.Morton, Contr. U.S. Nat. Herb. 26: 342. 1933.

Plants glabrous with leaves entire o minutely serrate; leaves and inflorescence black punctate.

Viburnum elatum es endémico de México, se distribuye a lo largo del territorio.

Subsección Prunifolia Villarreal \& A.E.Estrada, subsec. nov. Especie tipo: Viburnum prunifolium L.

Plants with pubescence of reddish stellate hairs; leaves serrate.

Viburnum rufidulum tiene distribución en los Estados Unidos y se extiende hasta el norte De Coahuila. Viburnum lentago L., V. ferrugineum (Torr. \& A. Gray) Small y $V$. prunifolium L. con distribución en Norteamérica, también se agrupan en esta subsección.

Sección Oreinotinus (Oerst.) Donoghue, Amer. J. Bot. 80: 146.1993.

Plantas con hojas usualmente dentadas, raramente enteras; cimas pedunculadas; estilos glabros o pubescentes; frutos ligeramente aplanados o no aplanados, con una intrusión en el endocarpo. Unas 38 especies distribuidas en México, Centro y Sudamérica.

Subsección Hartwegiana Villarreal \& A.E.Estrada, subsec. nov. Especie tipo: Viburnum hartwegii Benth.

Secc. Bracteata C.V.Morton, Contr. U.S. Nat. Herb. 26: 342. 1933.

Plants with leaves usually elliptic, entire, apex acute to acuminate; style glabrous; fruit spheroid; pyrene with a slight central intrusion.
Comprende tres especies: Viburnum costaricanum (Oerst.) Hemsley de Costa Rica y Panamá, y V. hartwegii y V. obtusatum con distribución en México y Centroamérica.

Subsección Acutifolia Villarreal \& A.E.Estrada, subsec. nov. Especie tipo: Viburnum acutifolium Benth.

Secc. Mexicana C.V.Morton, Contr. U.S. Nat. Herb. 26: 342. 1933.

Plants with leaves mostly elliptic to narrowly ovate, glabrous or with sparsely simple, forked hairs or glandular; style usually glabrous; fruit ellipsoid; pyrene with a slight central intrusion.

Dos especies: Viburnum venustum de Costa Rica y Panamá, y V. acutifolium del sur de México y Guatemala, con cuatro variedades: acutifolium, blandum, lautum y microphyllum.

Subsección Discolora Villarreal \& A.E.Estrada, subsec. nov. Especie tipo: Viburnum discolor Benth.

Secc. Disjuncta C.V.Morton, Contr. U.S. Nat. Herb. 26: 342. 1933.

Plants with leaves usually ovate, densely stellate-pubescent on the adaxial surface; corolla pubescent; style glabrous; pyrene and fruit moderately flattened; pyrene with a slight central intrusion.

Comprende cuatro especies del sur de México y Centroamérica, incluye a Viburnum discolor, $V$. disjunctum, $V$. jucundum y V. sulcatum. Morton (1933) relaciona a V. stellatotomentosum (Oerst.) Hemsl de Costa Rica y Panamá con este grupo de especies.

Subsección Microcarpa Villarreal \& A.E.Estrada, subsec. nov. Especie tipo: Viburnum microcarpum Schltdl. \& Cham.

Secc. Ciliata C.V.Morton, Contr. U.S. Nat. Herb. 26: 342. 1933. Secc. Caudata C.V.Morton, Contr. U.S. Nat. Herb. 26: 342. 1933. Secc. Serrata C.V.Morton, Contr. U.S. Nat. Herb. 26: 342. 1933.

Plants with leaves widely variable in shape, frequently ovate to elliptic, usually dentate; style pubescent; fruit slightly flattened; pyrene with a prominent central intrusion.

Comprende siete especies mexicanas: Viburnum caudatum, V. ciliatum, V. loeseneri, V. membranaceum, V. microcarpum, $V$. stenocalyx y $V$. tiliifolium.

Clave para las subsecciones, especies y variedades de Viburnum en México

1. Inflorescencias sésiles o con pedúnculos menores de $1 \mathrm{~cm}$ de largo, con (2)3-5 radios primarios.

2. Hojas e inflorescencia glabras; hojas con puntos negros en el envés, con margen entero a diminutamente serrulado (Subsecc. Elata) ...................................... V. elatum 2. Hojas e inflorescencia con pelos estrellados, rojizos; hojas sin puntos negros en el envés, con margen serrulado (Subsecc. Prunifolia)........................... V. rufidulum 1. Inflorescencias con pedúnculos de más de $1 \mathrm{~cm}$ de largo, con 5-7 radios primarios. 
3. Estípulas persistentes; hojas con dientes de 4-7 mm de ancho y largo; fruto aplanado; pireno sin surco central (Subsecc. Rafinesquiana). V. rafinesquianum 3. Estípulas caedizas; hojas con dientes menores de $4 \mathrm{~mm}$ de largo, denticuladas o enteras; fruto casi redondo a ligeramente aplanado; pireno usualmente con un surco central conspicuo.

4. Hojas ovado-lanceoladas, enteras y con el ápice acuminado-obtuso; fruto casi esférico (Subsecc. Hartwegiana).

5. Ramas e inflorescencia con pelos simples y glandulares; hojas de 2-6 cm de largo y 1-2 cm de ancho V. obtusatum

5. Ramas e inflorescencia con pelos simples y fasciculados; hojas de $5-15 \mathrm{~cm}$ de largo y $2-5 \mathrm{~cm}$ de ancho ..... V. hartwegii

4. Hojas no con la combinación de ser ovado-lanceoladas, enteras y con el ápice acuminado-obtuso; fruto elipsoidal.

6. Cimas de 1-2 cm de largo y 2-4 cm de ancho, glabras o con pubescencia escasa; hojas enteras a espaciadamente denticuladas (Subsecc. Acutifolia).

7. Hojas y lóbulos del cáliz sin cilios; estilo con pubescencia de pelos simples, raramente glabro; inflorescencia usualmente de 7 radios; plantas casi glabras ... ........................... V. acutifolium var. blandum 7. Hojas y lóbulos del cáliz frecuentemente ciliados; estilo glabro o con pocos pelos simples en la base; inflorescencia de 5-7 radios; plantas con pubescencia.

8. Ramas e inflorescencia con pubescencia de pelos simples y estrellados, 4-12 radios de menos de $1 \mathrm{~mm}$ de diámetro......... V. acutifolium var. microphyllum 8. Ramas e inflorescencia glabras a pubescentes de pelos simples y estrellados, la mayoría de menos de 4 radios de 1-2 mm de diámetro.

9. Cáliz con pelos glandulares rojizos; inflorescencia de 5 radios; de Oaxaca

V. acutifolium var. acutifolium

9. Cáliz glabro o con pocos pelos simples; inflorescencia (5-)7 radios; de Chiapas y Guatemala .......... V. acutifolium var. lautum

6. Cimas de 3-6 cm de largo y 4-12 cm de ancho, con pubescencia de pelos estrellados, simples o glandulares; hojas dentadas, raramente enteras.

10. Ramas, hojas e inflorescencia con pubescencia densa de sólo pelos estrellados; hojas con el margen dentado-glandular a entero; estilos glabros (Subsecc. Discolora).

11. Hojas con el haz glabro y el margen usualmente entero.................................... V. sulcatum 11. Hojas con el haz pubescente y el margen dentado, aserrado o entero.

12. Hojas ovadas a elípticas; margen dentado o denticulado; nervación conspicua.
13. Hojas usualmente ovadas; nervios no anastomosados hacia el margen; envés con pubescencia amarillenta..................... V. jucundum 13. Hojas usualmente elípticas a oblongas; nervios anastomosados hacia el margen; envés con pubescencia blanquecina V. discolor

12. Hojas ovado-lanceoladas a lanceoladas; margen usualmente entero; nervación inconspicua .. $V$ disjunctum

10. Ramas, hojas e inflorescencia con pubescencia mixta de pelos simples, estrellados o glandulares; hojas usualmente dentadas (enteras en algunas muestras de $V$. caudatum); estilos pubescentes (Subsecc. Microcarpa).

14. Hojas con pubescencia esparcida o restringida a los nervios; inflorescencias glabras o glandulares.

15. Pubescencia de ramillas y hojas de pelos simples y glandulares; 6-8 pares de nervios en las hojas.

16. Hojas con margen aserrado, ciliado; nervios no anastomosados hacia el margen ....... V. ciliatum

16. Hojas con el margen entero a ondulado o pocos dientes basales, no ciliadas; nervios anastomosados hacia el margen

V. caudatum

15. Pubescencia de ramillas y hojas de pelos simples y estrellados; 5-6 pares de nervios en las hojas .... V. membranaceum 14. Hojas con pubescencia densa en el envés; inflorescencias con pubescencia de pelos estrellados.

17. Cáliz con pubescencia de pelos estrellados; inflorescencias de 2-5 cm de ancho; hojas 3-5(-8) cm de largo V. loeseneri 17. Cáliz glabro o glandular; inflorescencias de 5-12 cm de ancho; hojas 5 $-12 \mathrm{~cm}$ de largo.

18. Hojas fuertemente discoloras; el haz glabro y envés blanco tomentoso; fruto 3-4 mm de largo ............ V. microcarpum 18. Hojas ligeramente discoloras; el haz con pubescencia estrellada, más densa en el envés; fruto 4-6 mm de largo.

19. Hojas ovadas a lanceoladas, $5-10 \mathrm{~cm}$ de largo y 3-5 cm de ancho, ciliadas; envés con pubescencia esparcida o restringida a la nervación ....................... V. stenocalyx 19. Hojas oblongas, rómbicas, ovadas a suborbiculares, 8-16 cm de largo y 4$12 \mathrm{~cm}$ de ancho, no ciliadas; envés con pubescencia densa V. tiliifolium 
Viburnum acutifolium Benth., Pl. Hartw. 59. 1840. Oreinotinus acutifolius (Benth.) Oerst., Vidensk. Meddel. Dansk Naturhist. Foren. Kjöbenhavn 1860: 293. 1861. TIPO: México. Oaxaca, on the Pelado, 1839, K. T. Hartweg 449 (Holotipo: K000573709!; Isotipo LD 12462031).

Arbustos o árboles de hasta $10 \mathrm{~m}$ de alto; ramas glabras o con pubescencia escasa de pelos simples a bifurcados y/o pelos estrellados. Hojas con estípulas caedizas, con pecíolos de 3-10 mm de largo, surcados, glabros o con pubescencia escasa; limbos oblongos, ovados a lanceolados, de 3-9 cm de largo, 2-5 cm de ancho, base cuneada, ápice fuertemente acuminado, margen entero a espaciadamente denticulado, usualmente ciliado, con 4-8 nervios laterales, no anastomosados, haz y envés glabros o con pelos simples a bifurcados a lo largo de las nervaduras, verde claro, membranáceos a subcoriáceos, ligeramente discolores. Inflorescencias 1-2 veces compuestas, de 10-18 cm de largo, 2-4(-10) $\mathrm{cm}$ de ancho, pedúnculos de 2-4 cm de largo, radios primarios 5(7), de $8-12 \mathrm{~mm}$ de largo, pedicelos de $2-6 \mathrm{~mm}$ de largo, glabros o con pelos simples o bifurcados y glándulas rojizas, bractéolas linear-lanceoladas, 4-7 mm de largo; cáliz estrechamente campanulado, usualmente con pelos simples y pelos glandulares rojos, tubo de cerca de $2 \mathrm{~mm}$ de largo, lóbulos deltoideos de 0.2-0.4 mm de largo, ciliados; corola campanulada, tubo de 2-3 mm de largo, lóbulos extendidos, de 2-3 mm de largo, glabra, blanca; estambres de 4-5 mm de largo; estilo glabro o con pubescencia escasa. Fruto elipsoide a ligeramente ovado, de 6-9 $\mathrm{mm}$ de largo, 3-6 mm de ancho, glabro, púrpura oscuro; pireno de 3-4 mm de largo, 1.5-3 mm de ancho, con surco central tenue.

Viburnum acutifolium comprende una serie de poblaciones en el sur y occidente del país que tienden a diferenciarse por una combinación de características de la pubescencia, inflorescencia y distribución. Debido a la diferenciación parcial entre las poblaciones, en el presente trabajo se considera a la especie como formada por cuatro variedades, como se muestra en la clave y en las descripciones. Donoghue (1982) las consideró como subespecies, sin haberlas publicado formalmente.

\section{Viburnum acutifolium Benth. var. acutifolium}

Oreinotinus fuscus Oerst., Vidensk. Meddel. Dansk Naturhist. Foren. Kjöbenhavn 1860: 289. 1861. V. fuscum (Oerst.) Hemsl., Biol. Centr. Amer. Bot. 2: 3. 1881. TIPO: México. Oaxaca, Totontepec, jul. 1842, F. M. Liebmann 7809 (Lectotipo: C; Isolectotipo: K000573711!, designado por Donoghue (1982)).

Arbustos o árboles de hasta $10 \mathrm{~m}$ de alto; ramas glabras o con pubescencia escasa de pelos simples a bifurcados y/o pelos estrellados de 1-2 mm de diámetro. Hojas sin estípulas, con pecíolos de 6-10 mm de largo, surcados, glabros o

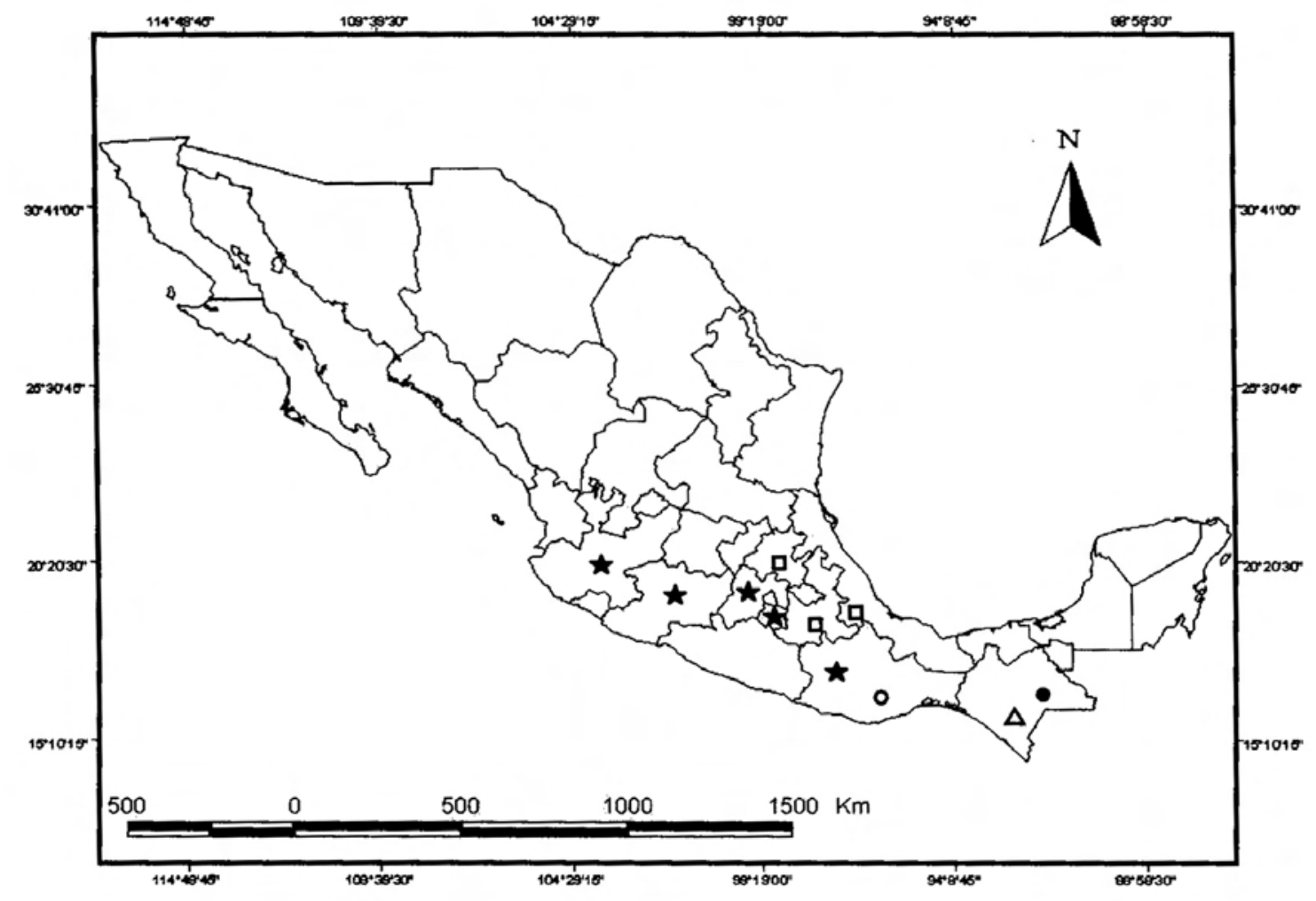

Figura 2. Distribución conocida en México de Viburnum acutifolium var. acutifolium (círculos blancos), V. acutifolium var. blandum (círculos negros), V. acutifolium var. lautum (triángulos), V. acutifolium var. microphyllum (estrellas) y V. caudatum (cuadros). 
con pubescencia escasa; limbos ovados a lanceolados, de 3-6 cm de largo, 2-4 cm de ancho, base cuneada, con ápice fuertemente acuminado, margen entero, usualmente ciliado, con 4-6 nervios laterales, no anastomosados, con pubescencia a lo largo de las nervaduras, verde claro, subcoriáceos, ligeramente discolores. Inflorescencias $1 \mathrm{vez}$ compuestas, de 10-18 mm de largo, 2-4 cm de ancho, con pedúnculos de 2-3 cm de largo, glabros o con pelos simples y estrellados, radios primarios 5, pedicelos de 3-6 $\mathrm{mm}$ de largo, glabros o con pelos simples y estrellados, bractéolas linear-lanceoladas, 4-7 mm de largo; cáliz estrechamente campanulado, con pelos glandulares rojos, tubo de cerca de $2 \mathrm{~mm}$ de largo, lóbulos deltoideos de 0.2-0.4 mm de largo, ciliados; corola campanulada, glabra, blanca, tubo de 2-3 mm de largo, lóbulos extendidos, de 2-3 mm de largo; estambres de 4-5 $\mathrm{mm}$ de largo; estilo glabro. Fruto elipsoide a ligeramente ovado, de 4-7 mm de largo, 3-6 mm de ancho, glabro, púrpura oscuro; pireno de 3-4 mm de largo, 1.5-2 $\mathrm{mm}$ de ancho con surco central tenue.

Distribución y hábitat. Endémica de México, solo se conoce de Oaxaca (Figura 2). Crece a lo largo de arroyos y caminos en bosques de pino-encino y mesófilo de montaña, en elevaciones de 1,900-3,000 m. Florece de abril a junio. Planta relativamente abundante, sin problemas inmediatos de supervivencia.

Comentario taxonómico. La variedad tipo de la especie se distribuye al norte del Istmo de Tehuantepec y se caracteriza por presentar cáliz con pelos glandulares rojizos, inflorescencia de 5 radios y pubescencia escasa a moderada de pelos simples a bifurcados o estrellados de 4-5(-10) radios de 1-2 mm de diámetro. De acuerdo con Donoghue (1982), los ejemplares sintipos colectados por Liebmann $(7809,7810$ y 7811) presentan características entre las variedades $a c u$ tifolium y blandum, y son en los que Morton (1933) se basa para distinguir a V. fuscum.

Ejemplares examinados. OAXACA: Mpio. San Juan Juquila, Dto. Villa Alta, $2.2 \mathrm{~km}$ al $\mathrm{N}$ de entronque Talea-Tanetze, camino real a Tanetze, Sierra Norte, Aguilar 813 (MEXU); Mpio. Cuicatlán, Dto. Cuicatlán, Cerro de Santa María Pápalo, Conzatti y González 766 (MEXU); Mpio. San Miguel Chimalapa, cima del Cerro Salomón, al NW de Benito Juárez, $c a$. 44 km en línea recta al N de San Pedro Tapantepec, Ishiki 1301 (MEXU); Dto. Ixtlán, Sierra de Juárez, camino de Natividad a Talea de Castro, $2 \mathrm{~km}$ al SW de la desviación a Yalina (comedor Maravillas), Lorence 4699 (MEXU); Mpio. Totontepec, Dto. Mixe, $11.4 \mathrm{~km}$ al SW de Ayutlán, carretera Totontepec-Mitla, Torres 7046 (MEXU).

Viburnum acutifolium Benth. var. blandum (C.V.Morton) Villarreal \& A.E.Estrada, var. nov. V. blandum C.V.Morton, Contr. U.S. Nat. Herb. 26: 352. 1933. TIPO: México. Chia- pas, Pinabete, 8 feb. 1896, E. W. Nelson 3782 (Holotipo: US00130225!; Isotipo: GH).

Viburnum optatum C.V.Morton, Contr. U.S. Nat. Herb. 26: 358. 1933. TIPO: Guatemala. Depto. Huehuetenango, Jacaltenango, G. E. Seler 2639 (Holotipo: GH; Isotipo: NY!). V. optatum C.V.Morton var. vagum C.V.Morton, Contr. U.S. Nat. Herb. 26: 359. 1933. TIPO: Guatemala. Depto. Quiché, San Miguel Uspantán, abr. 1892, E. T. Heyde \& E. Lux in J. D. Smith 3042 (Holotipo: US00139029!; Isotipos: F0053211f!, GH, NY!). V. blandum C.V.Morton var. vulcanicum C.V.Morton, Proc. Biol. Soc. Wash. 49: 154. 1936. TIPO: Guatemala. Depto. Suchitepequez, S slope of volcán Atitlán, 14 ene. 1935, A. F. Skutch 2125 (Holotipo: US00130226!; Isotipos: A, F0053192f!, US). V. montanum Lundell, Lloydia 2: 106. 1939. TIPO: México. Chiapas, Mt. Ovando, jul. 1938, E. Matuda 2564 (Holotipo: MICH1192101!).

Arbustos o árboles pequeños de hasta $10 \mathrm{~m}$ de alto; ramas glabras (raramente con pubescencia escasa de pelos simples y pelos glandulares). Hojas sin estípulas, con pecíolos de 3$8 \mathrm{~mm}$ de largo, surcados, glabros, ocasionalmente con glándulas rojizas; limbos oblongos a lanceolados, de 3-12 cm de largo, 2-5 cm de ancho, base cuneada a redondeada, ápice fuertemente acuminado, margen entero a denticulado, con 4-6 nervios laterales, no anastomosados, glabras, sin cilios, ocasionalmente con glándulas rojizas y pelos simples, verde claro, membranáceos, ligeramente discolores. Inflorescencias $1 \mathrm{vez}$ compuestas, de 10-16 mm de largo, 2-4 cm de ancho, con pedúnculos de 2-4 cm de largo, glabros u ocasionalmente con glándulas rojizas y pocos pelos simples; radios primarios 7 , pedicelos de 2-4 $\mathrm{mm}$ de largo, bractéolas linear-lanceoladas, 4-7 mm de largo; cáliz estrechamente campanulado, glabro o con pelos simples, tubo $\mathrm{ca}$. de $2 \mathrm{~mm}$ de largo, lóbulos deltoideos de 0.2-0.4 mm de largo, no ciliados; corola campanulada, tubo de 2-3 mm de largo, lóbulos extendidos, de 2-3 mm de largo, glabra, blanca; estambres de 4-5 mm de largo; estilo con pubescencia esparcida de pelos simples, raramente glabro. Frutos elipsoides a ligeramente ovados, de 4-7 mm de largo, 3-6 mm de ancho, glabro, púrpura oscuro; pireno de 3-4 mm de largo, 2-3 $\mathrm{mm}$ de ancho, con surco central tenue.

Distribución y hábitat. Se distribuye en el extremo sur de México (Figura 2), extendiéndose hasta Guatemala y El Salvador. Crece a orilla de arroyos y ríos en bosques de encino-pino y mesófilo de montaña, en elevaciones de 1,8002,800 m. Florece de abril a junio. Especie con problemas de supervivencia debido al desarrollo urbano y el uso de la tierra para agricultura, es considerada como vulnerable.

Comentario taxonómico. La variedad blandum es la más meridional, se caracterizan por ser plantas prácticamente 
glabras, con pubescencia escasa de pelos simples y estilo usualmente pubescente. Donoghue (1982) establece dos variantes, la de la Planicie Central y la de la Sierra Madre de Chiapas. Las diferencias estriban principalmente en que la primera presenta hojas usualmente con nervación notoria y con base usualmente redondeada ( $v s$. usualmente cuneada), pecíolos frecuentemente de más de $10 \mathrm{~mm}$ de largo, inflorescencia predominantemente de más de $7 \mathrm{~cm}$ de ancho y de 7 radios principales ( $v s .5-7$ radios), y estilo pubescente ( $v s$. usualmente glabro).

Ejemplares examinados. CHIAPAS: Mpio. San Cristóbal de las Casas, E side of Zonthehitz near summit, Breedlove 30429 (ENCB), 53584 (ENCB); Mpio. La Grandeza, 10 km $\mathrm{E}$ of the Porvenir along road from Huixtla to Siltepec, Breedlove 31825 (ENCB); Mpio. Motozintla de Mendoza, high ridge with evergreen cloud forest near Niquivil at the junction with a small side ridge to Cerro Boquerón, Breedlove 42763 (ENCB); Mpio. Motozintla de Mendoza, 11 km NW of the junction of the road to Motozintla along the road to El Porvenir and Siltepec, SW side of Cerro Mozotal, Breedlove 55736 (ENCB).

Viburnum acutifolium Benth. var. lautum (C.V.Morton) Villarreal \& A.E.Estrada, var. nov. V. lautum C.V.Morton, Contr. U.S. Nat. Herb. 26: 351. 1933. TIPO: México. Chiapas, 1864, A. B. Ghiesbreght 517 (Holotipo: GH; Isotipos: BM000630201!, K000573716!, MO159205!, NY).

Viburnum tacanense Lundell, Lloydia 2: 107. 1939. TIPO: México. Chiapas, Mt. Tacaná, ago. 1938, E. Matuda 2332 (Holotipo: MICH1192103!; Isotipos: A, F, GH, K000573713!, MEXU, MICH, NY, US00139043!). V. amatenangense Lundell, Wrightia 3: 170. 1966. TIPO: México. Chiapas, Amatenango del Valle, 12 jun. 1945, E. Matuda 5854 (Holotipo: LL; Isotipos: K000573712!, MEXU, TEX). V. siltepecanum Lundell, Wrightia 3: 171. 1966. TIPO: México. Chiapas, cascada near Siltepec, 3 mar. 1945, E. Matuda 5111 (Holotipo: LL00373214!; Isotipos: CAS0004984!, F0053212f!, MEXU, TEX).

Arbustos de hasta $6 \mathrm{~m}$ de alto; ramas con pocos pelos simples o frecuentemente con pubescencia de pelos bifurcados a pentafurcados de 1-2 mm de diámetro. Hojas sin estípulas, con pecíolos de 3-6 $\mathrm{mm}$ de largo, surcados, con pubescencia escasa de pelos simples o bifurcados; limbos oblongos a lanceolados, de 2-7 cm de largo, 1-4 cm de ancho, base cuneada, ápice acuminado, margen entero, usualmente ciliado, con 4-6 nervios laterales, no anastomosados, pelos simples a bifurcados, ocasionalmente con glándulas rojizas a lo largo de las nervaduras, verde claro, subcoriáceos, ligeramente discolores. Inflorescencias $1 \mathrm{vez}$ compuestas, de 10-18 mm de largo, 2-4 cm de ancho, con pedúnculos de 2-3 cm de largo, cubiertas por pelos bifurcados a tetrafurcados, radios
(5-)7, pedicelos de 3-5 mm de largo, bractéolas linear-lanceoladas, 4-7 mm de largo; cáliz estrechamente campanulado, glabro o con pocos pelos simples, tubo de cerca de $2 \mathrm{~mm}$ de largo, lóbulos deltoideos de 0.2-0.4 mm de largo, ciliados; corola campanulada, tubo de 2-3 mm de largo, lóbulos extendidos, de 2-3 mm de largo, glabra, blanca; estambres de 4-5 $\mathrm{mm}$ de largo; estilo con pubescencia escasa de pelos simples a glabro. Frutos elipsoides a ligeramente ovados, de 4-7 mm de largo, 3-6 mm de ancho, glabros, púrpura oscuros; pirenos de 3-4 mm de largo, 1.5-2 mm de ancho, con surco central tenue.

Distribución y hábitat. Se distribuye en el extremo sur de México (Figura 2), extendiéndose hasta Guatemala. Crece en bosque tropical, en elevaciones de 1,500-2,000 m. Florece de mayo-agosto. Elemento escaso en el área donde habita, debido al desarrollo urbano y cambios en el uso del suelo por la agricultura y ganadería, se le considera vulnerable. Nombres comunes. Se le conoce como Chak jolob te (Tojolabal), bik tal stop y ta tí beja (Tzeltal).

Comentario taxonómico. La variedad lautum se distribuye al sur del Istmo de Tehuantepec presenta pubescencia moderada a ligeramente densa de pelos simples y estrellados de 1-2 mm de diámetro, el cáliz glabro o con pocos pelos simples e inflorescencia con (5-)7 radios.

Ejemplares examinados. CHIAPAS: Mpio. San Cristóbal de las Casas, Sierra de Salsipuedes at the S side of valley of San Cristóbal de las Casas, Breedlove 40675 (ENCB); Mpio. Chamula, Cruz Chot, $500 \mathrm{~m}$ al SE de la escuela Cruz Chot, Gómez 98 (ANSM); Mpio. Teopisca, propiedad comunal $2 \mathrm{~km}$ de Teopisca hacia la montaña, López 88 (ANSM); Mpio. San Cristóbal de las Casas, arroyo del Rancho Pellizzi, al E de San Cristóbal, Méndez 9178 (ENCB); Mpio. San Cristóbal de las Casas, Santa Cruz en San Felipe, Méndez 9866 (ENCB); Mpio. Margaritas, $700 \mathrm{~m}$ al SE de la comunidad de Santa Rita Sonora, Santiz 4 (ANSM), Santiz 533 (ENCB); Mpio. San Juan Chamula, Joinajojtic, Santiz 896 (ENCB, TEX).

Viburnum acutifolium Benth. var. microphyllum (Oerst.) Villarreal \& A.E.Estrada, var. nov. Oreinotinus microphyllus Oerst., Vidensk. Meddel. Dansk Naturhist. Foren. Kjöbenhavn 1860: 293. 1861. TIPO: México. Oaxaca, cuesta de San Pedro Alto, F. M. Liebmann 7816 (Holotipo: C10009076!). V. microphyllum (Oerst.) Hemsl., Biol. Centr. Amer. Bot. 2: 3. 1881.

Viburnum dispar C.V.Morton, Contr. U.S. Nat. Herb. 26: 253. 1933. TIPO: México. Jalisco, canyons at base of Nevado de Colima, 23 may. 1893, C. G. Pringle 4384 (Holotipo: US!; Isotipos: A, BM000630213!, CAS, F, GH, K000573710!, MO15 9307!, MSC, NY). 
Arbustos o árboles pequeños de hasta $8 \mathrm{~m}$ de alto; ramas con pubescencia estrellada (4-12 radios) de menos de $1 \mathrm{~mm}$ de diámetro, glabrescentes en la madurez. Hojas sin estípulas, con pecíolos de 4-9 mm de largo, ligeramente surcados, con pubescencia de pelos simples de hasta $2 \mathrm{~mm}$ de largo y pelos estrellados de hasta $0.6 \mathrm{~mm}$ de diámetro; limbos oblongos a lanceolados, de 3-10 cm de largo, 2-5 cm de ancho, base cuneada, ápice acuminado, margen entero, usualmente ciliado, con 4-8 nervios laterales, no anastomosados, pelos estrellados a lo largo de las nervaduras, verde claro, subcoriáceos, ligeramente discolores. Inflorescencias 1 vez compuestas, de 10-18 mm de largo, 2-4 cm de ancho, con pedúnculos de 2-3 cm de largo, con pubescencia estrellada de menos de $1 \mathrm{~mm}$ de diámetro, radios 5-7, pedicelos de 3-6 mm de largo, bractéolas linear-lanceoladas, 4-7 mm de largo; cáliz estrechamente campanulado, con pelos simples y glandulares rojos, tubo de cerca de $2 \mathrm{~mm}$ de largo, lóbulos deltoideos de 0.2-0.4 mm de largo, ciliados; corola campanulada, tubo de 2-3 mm de largo, lóbulos extendidos, de 2-3 mm de largo, glabra, blanca; estambres de 4-5 mm de largo; estilo glabro o con pocos pelos simples en la base. Frutos elipsoides a ligeramente ovados, de 6-8 mm de largo, 3-6 mm de ancho, glabros, púrpura oscuros; pirenos de 3-4 mm de largo, 2-3 mm de ancho, con surco central tenue.

Distribución y hábitat. Endémica de México, se distribuye en el centro-occidente del país (Figura 2). Crece en laderas de cerros y cañadas, en bosques de pino-encino con elementos mesófilos, en elevaciones de 1,300-2,900 m. Florece de mayo a julio. Elemento relativamente abundante en las áreas de distribución, por lo que no tiene problemas inmediatos de supervivencia.

Nombres comunes. Locamente conocido como garambullo o jazmín.

Comentario taxonómico. La variedad microphyllum tiene distribución en el oeste y un poco en el centro del país y presenta pubescencia de pelos estrellados de menos de $1 \mathrm{~mm}$ de diámetro, inflorescencias con 5-7 radios, cáliz con pelos simples y glandulares rojos y estilo generalmente glabro.

Ejemplares examinados. JALISCO: Nevado de Colima, N slope, below La Joya, Boutin 2354 (MEXU); Mpio. Autlán, Sierra de Manantlán, por Neverías, Cházaro 4539 (IBUG, IEB); NW slope of Nevado de Colima, in Pinefir zone above Jazmin, $1 \mathrm{~km}$ above settlement of El Isote, McVaugh 10026 (ENCB, TEX); Mpio. Ciudad Guzmán, $8 \mathrm{~km}$ camino del Fresnito hacia el Nevado de Colima, Reynoso 2195 (MEXU, NY); MÉXICO: Valle de Bravo, Boege 1763 (MEXU); Mpio. Temascaltepec, Cieneguillas a $14 \mathrm{~km}$ al N de Temascaltepec, Moreno 178 (ENCB); MICHOACÁN: Mpio. Pátzcuaro, Cerro El Estribo, Caballero 1047 (MEXU); Mpio. Morelia, El Tanque, al S de San Miguel del Monte, Díaz 7268 (IEB, MEXU, TEX); Mpio.
Angangueo, Barranca Honda, Sierra de Chincua, Mejía s. n. (IEB): MORELOS: Sin datos, Vázquez 2188 (ENCB); OAXACA: Mpio. Ixtlán de Juárez, $5 \mathrm{~km}$ al N de Comaltepec, Cedillo 620 (MEXU); Mpio. San Felipe Usila, cuenca del Río Perfume (ladera W), $9.1 \mathrm{~km}$ en línea recta al S de Santa Cruz Tepetotula, Meave 1678 (MEXU); Mpio. Totontepec, Dto. Mixe, Cerro La Mitra, a $5 \mathrm{~km}$ de Totontepec, $R a$ mírez 753 (MEXU); Mpio. San Felipe Usila, 5.6 km en línea recta al S de Santa Cruz Tepetotula, Rincón 229 (MEXU), 230 (MEXU); Dto. Mixe, $2.5 \mathrm{~km}$ de la entrada a Villa Alta, brecha a Tiltepec, la entrada a $8.5 \mathrm{~km}$ al S de Totontepec, Tenorio 11088 (MEXU).

Viburnum caudatum Greenm., Proc. Amer. Acad. Arts 41: 250. 1905. TIPO: México. Hidalgo, barranca abajo de las minas de hierro La Trinidad, 24 may. 1904, C. G. Pringle 8826 (Holotipo: GH00094303!; Isotipos: BM, CAS, E00259172!, F, GOET, K000573704!, LL, NY, PH, US00130233!).

Arbustos o árboles de 3-6 m de alto; ramas glabras o con pubescencia glandular. Hojas con estípulas caedizas, con pecíolos de 6-16 mm de largo, ligeramente surcados, con pelos glandulares; limbos rómbicos a ovados, de $6-12 \mathrm{~cm}$ de largo, 4-8 cm de ancho, base cordada a redondeada, ápice abruptamente acuminado, margen entero a ondulado, en ocasiones con 3-4 dientes glandulares en la porción basal, 4-6 pares de nervios, anastomosados hacia el margen, haz glabrescente, de color verde, envés glandular, con pelos estrellados en las axilas de las venas, de color verde pálido, membranáceos, ligeramente discolores. Inflorescencias 2(3 ) veces compuestas, de 3-4 cm de largo, 4-8 cm de ancho; pedúnculos de $3-5 \mathrm{~cm}$ de largo, radios primarios $5-7$, de 1-2 cm de largo, radios secundarios 4-6, de 8-12 mm de largo, pedicelos de 1-6 mm de largo, con pelos glandulares, bractéolas lineares, de 3-4 mm de largo, glandulares; cáliz cilíndrico a estrechamente campanulado, con pelos glandulares, tubo de 1-2 mm de largo, lóbulos triangulares, de ca. $1 \mathrm{~mm}$ de largo, usualmente sin cilios; corola rotada, tubo de 1-2 mm de largo, lóbulos extendidos, de 2-2.5 mm de largo, glabra, blanca; estambres de $5 \mathrm{~mm}$ de largo; estilo villoso. Frutos elipsoides, bilobados, ligeramente aplanados, de 4$6 \mathrm{~mm}$ de largo, 3-4 mm de ancho, glabros, negros; pirenos de 3-4 mm de largo, 2-3 mm de ancho, con surco central.

Distribución y hábitat. Endémica de México, se distribuye en la región centro (Figura 2). Crece en laderas de cerros y orillas de ríos en bosque de encino, en elevaciones de 1,0002,200 m. Florece de marzo a junio. Dada su frecuencia, la especie no se considera vulnerable.

Ejemplares examinados. HIDALGO: Mpio. Tenango de Doria, El Damo, aprox. $2 \mathrm{~km}$ al E de Tenango de Doria, Alcántara 1017 (MEXU); Mpio. Zacualtipan, Cumbre de Tlahuelompa, $7 \mathrm{~km}$ del entronque que da a la carretera fe- 
deral Zacualtipan-Metzquititlán, López 81 (IEB, MEXU); Barranca below Trinidad iron works, Pringle 10037 (NY); PUEBLA: Mpio. La Unión, $6 \mathrm{~km}$ al E de Xicontepec, carretera a La Unión, Campos 97 (MEXU); Mpio. Tlapacoya, $2 \mathrm{~km}$ al W de Tlapacoya, Contreras 4192 (HUAP, MEXU); Mpio. Ahuacatlán, Agua Dulce, 4 km al SE de Ahuacatlán, Tenorio 8983 (MEXU); Mpio. Hueytamalco, sección séptima de Hueytamalco, Ventura 676 (ENCB); VERACRUZ: Mpio. Jalacingo, Agua Cruz, Ventura 1171 (ENCB).

Viburnum ciliatum Greenm., Proc. Amer. Acad. Arts 41: 251. 1905. TIPO: México. Hidalgo, bosques húmedos cerca de las minas de hierro La Trinidad, 30 abr. 1904, C. G. Pringle 8881 (Holotipo: GH00094304!; Isotipos: BM, CAS, E, F, GOET, K000573705!, NY00278606!, P, PH, US).

Arbustos o árboles de 3-6 m de alto; ramas con pubescencia hirsútula esparcida, glabras en la madurez. Hojas con estípulas caedizas, con pecíolos de 6-18 mm de largo, surcados, esparcidamente hirsútulos; limbos rómbicos a ovados, de 4-8 cm de largo, 2-6 cm de ancho, base cordada a ligeramente cuneada, ápice acuminado, margen aserrado, cada diente terminando en un mucrón glandular, correspondiendo a la terminación de cada nervio, 6-8 pares de nervios no anastomosados, pubescencia de pelos simples, hirsútulo en la venación, haz glabrescente, envés glandular, ciliados, verde claro, membranáceos, ligeramente discolores. Inflo- rescencias 1-2 veces compuestas, de 3-4 cm de largo, 4-6 cm de ancho; pedúnculos de 1-4 cm de largo, glandulares, hirsútulos a glabros, radios primarios 5-6, de 1-2 cm de largo, radios secundarios 4-6, de 10-16 mm de largo, pedicelos de 1-6 mm de largo, glandulares, hirsútulos a glabros, bractéolas lineares, de 3-4 mm de largo, ciliadas; cáliz cilíndrico a estrechamente campanulado, glabro, tubo de 1-2 mm de largo, lóbulos triangulares, de $c a .1 \mathrm{~mm}$ de largo, sin cilios; corola rotada, tubo de 1-2 mm de largo, lóbulos oblongos, extendidos, de 2-2.5 mm de largo, glabra, blanca; estambres de $3 \mathrm{~mm}$ de largo; estilo pubescente. Frutos elipsoides, bilobados, ligeramente aplanados, de 3-4 mm de largo, 2-3 mm de ancho, glabros, negros; pirenos de 2-3 mm de largo, 1.5$2.5 \mathrm{~mm}$ de ancho, con surco central.

Distribución y hábitat. Endémica de México, se distribuye en el occidente y centro del país (Figura 3). Crece en vegetación secundaria en bosques de pino, pino-encino, mesófilo de montaña y encinar, en elevaciones de 1,200-2,300 m. Florece de marzo a junio. Dada su frecuencia, la planta no se considera vulnerable.

Nombre común. En algunas partes se le conoce como platanillo.

Ejemplares examinados. GUERRERO: Mpio. Coyuca de Catalán, Las Palancas, $65 \mathrm{~km}$ al NE de Petatlán, González 6613 (IEB, MEXU); Mpio. Chichihualco, Cerro La Pastilla,

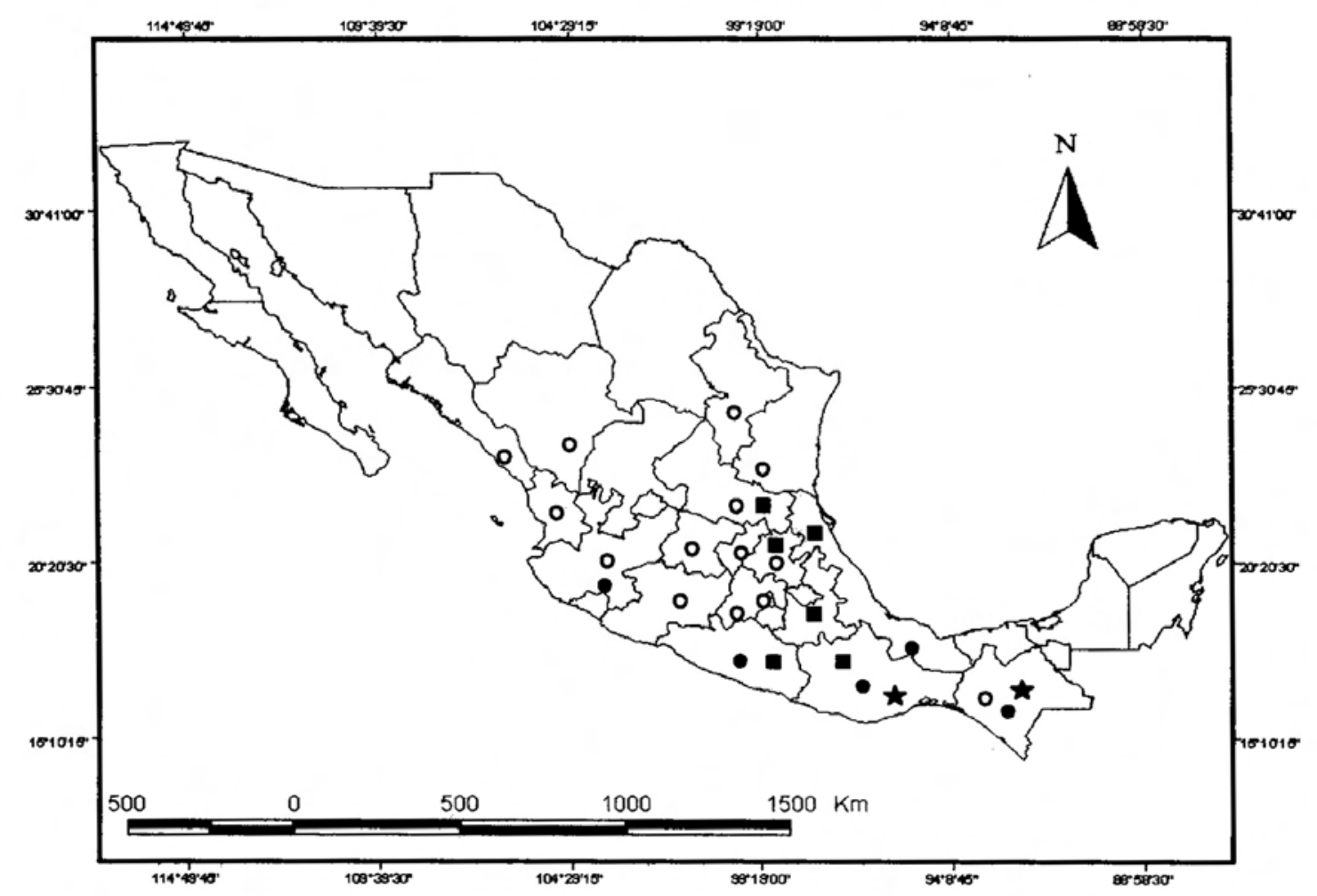

Figura 3. Distribución conocida en México de Viburnum ciliatum (cuadros negros), Viburnum elatum (círculos blancos), V. hartwegii (círculos negros) y V. obtusatum (estrellas). 
cerca de Camotla, Rzedowski 16457 (ENCB, NY); HIDALGO: Mpio. Zacaualtipan de Ángeles, El Reparo, aprox. 3.5 km al SW de Tlahuelompa, Alcántara 2089 (MEXU) Mpio. Tenango de Doria, $30 \mathrm{~km}$ al NE de Tulancingo, camino entre Metepec y Tenango de Doria, sobre un cerro muy empinado, Charles 5346 (ENCB); Mpio. Huasca, $16 \mathrm{~km}$ al S de Huasca, Hernández 5755 (ENCB); Mpio. Chico, puente Bandola, camino Omitán- Carboneras, Medina y Cota 3590 (ENCB, IEB); OAXACA: Mpio. San Felipe Usila, parteaguas del Río Perfume, $10.5 \mathrm{~km}$ en línea recta al S de Santa Cruz Tepetotula, Ibarra 3984 (MEXU); Mpio. San Juan Mixtepec, cañada de Tziqui, Cuaza a 8 km de San Juan Mixtepec, Reyes 905 (IEB, MEXU); Mpio. San Juan Mixtepec, Peña Blanca, $12 \mathrm{~km}$ al W de San Juan Mixtepec, Reyes 346 (IEB, MEXU); Mpio. San Juan Mixtepec, Dto. Joxtlahuaca, cañada de San Isidro, a $1 \mathrm{~km}$ al NW de Xucu Shuun, límite con San Martín Itanyoso, Reyes 2575 (MEXU); PUEBLA: Mpio. Zacapoastla, carretera Zacapoastla-Xochitlán, Zolá 287 (ENCB, MEXU, NY, XAL); SAN LUÍS POTOSÍ: Mpio. Xilitla, sierra de Xilitla, Paray 488 (ENCB); VERACRUZ: Mpio. Huayacocotla, atrás de la fábrica antigua de aguardiente, Calzada 2644 (XAL); Mpio. Tepetzintla, cerca de Otontepec, Castillo 2499 (XAL); Mpio. Huayacocotla, Agua de la Calabaza, $16 \mathrm{~km}$ al NE de Huayacocotla, Juárez \& Vázquez 71 (XAL); Mpio. Chinconquiaco, Planta El Pie, orilla de arroyo, Ventura 5138 (ENCB, IEB, MEXU, XAL).

Viburnum discolor Benth., Pl. Hartw. 83. 1841. TIPO: Guatemala. Montibus Totonicapán, 1840, K. T. Hartweg 579 (Holotipo: K000573700!; Isotipos: BM, E, F, LD, P). Oreinotinus discolor (Benth.) Oerst., Vidensk. Meddel. Dansk Naturhist. Foren. Kjöbenhavn 1860: 287. 1861.

Viburnum discolor Benth. var. subcordatum C.V.Morton, Proc. Biol. Soc. Wash. 49: 153. 1936. TIPO: Guatemala. Chimaltenango, Chichavac, 1933, A. F. Skutch 755 (Holotipo: US00130244!).

Arbustos o árboles pequeños de 3-7 m de alto; ramas con pubescencia de pelos estrellados, glabrescentes en la madurez. Hojas con estípulas caedizas, con pecíolos de 10-16 mm de largo, surcados, cubiertos por pelos estrellados; limbos elípticos a oblongos, en ocasiones oblongo-ovados, de 4-8 cm de largo, 2-5 cm de ancho, base cuneada, redondeada a ligeramente cordada, ápice acuminado, margen dentado, cada diente termina en un mucrón glandular, raramente entero, 4-5 pares de nervios curvados y conspicuos en el envés, con venación secundaria anastomosada, el haz con pubescencia escasa de pelos estrellados, más densa y blanquecina en el envés, subcoriáceos, discolores. Inflorescencias 3 veces compuestas, de 3-4 cm de largo, 4-6 cm de ancho, pedúnculos de 5-7 cm de largo, con pubescencia estrellada densa, radios primarios 5-6, de 12-18 $\mathrm{mm}$ de largo, radios secundarios 4-6, de 6-8 $\mathrm{mm}$ de largo, pedicelos de 1-6 $\mathrm{mm}$ de largo, con pubescencia estrellada densa, bractéolas lineares, de 3-4 mm de largo; cáliz estrechamente campanulado, pubescencia estrellada, tubo de 1-2 mm de largo, lóbulos ovados, de $c a .1 \mathrm{~mm}$ de largo, ciliados; corola campanulada, tubo de 2-3 mm de largo, lóbulos oblongos, extendidos, de 2-2.5 mm de largo, pubescente, blanca; estambres de $3 \mathrm{~mm}$ de largo; estilo glabro. Frutos elipsoides, bilobados, de 3-4 $\mathrm{mm}$ de largo, 2-3 mm de ancho, pubescentes, negros; pirenos de 2-3 $\mathrm{mm}$ de largo, 1.5-2 mm de ancho, con surco central tenue.

Distribución y hábitat. Se distribuye en el sur de México (Figura 4) y Guatemala. Crece en bosques de pino-encino, encino y bosque mesófilo de montaña, en elevaciones de 2,300-3,000 m. Florece de abril a junio. Planta poco frecuente, es considerada como vulnerable.

Ejemplares examinados. CHIAPAS: Mpio. Motozintla de Mendoza, SW of the junction of the road to Motozintla along the road to El Porvenir and Siltepec, Breedlove 46188 (MEXU, TEX); $6.5 \mathrm{~km} \mathrm{SW}$ of El Rosario along road to Ojo de Agua and Niquivil, Breedlove 65605 (MEXU, TEX); OAXACA: Mpio. San Pablo Macuiltianguis, a $10 \mathrm{~km}$ de la entrada por la Puerta del Sol, Calzada 4993 (MEXU); Dto. Villa Alta, $3 \mathrm{~km}$ al $\mathrm{S}$ de la desviación a Juquilla camino a Talea, Cedillo 2381 (MEXU); Dto. Villa Alta, $6 \mathrm{~km}$ al NE del entronque Nixistlán-Totontepec, hacia San Andrés Yaa, Torres 487 (MEXU).

Viburnum disjunctum C.V.Morton, Contr. U.S. Nat. Herb. 26(7): 356. 1933. TIPO: Guatemala. Alta Verapaz, Cobán, jun. 1886, H. von Tuerckheim 977 (Holotipo: US00130245!; Isotipos: GH, K000573703!, NY).

Viburnum disjunctum C.V.Morton var. mendax (C.V.Morton) D.N.Gibson, Phytologia 25(3): 114. 1973. V. mendax C.V.Morton, Proc. Biol. Soc. Wash. 49: 154. 1936. TIPO: Guatemala. Quiché, at Nejab, 10 dic. 1934, A. F. Skutch 1885 (Holotipo: A00031671!).

Árboles de 3-7 m de alto; ramas con pubescencia densa de pelos estrellados. Hojas con estípulas caedizas, con pecíolos de 1-2 cm de largo, surcados, con abundantes pelos estrellados; limbos ovado-lanceolados a elíptico-lanceolados, de 8-18 cm de largo, 5-8 cm de ancho, base cuneada a redondeada, ápice acuminado a apiculado, margen entero, menos frecuentemente serrulado en la base, dientecillos glandulares, con 6-7 pares de nervios curvados, anastomosados hacia el margen, nervación inconspicua, haz con pubescencia escasa de pelos estrellados, verde, envés densamente pubescente, grisáceo, subcoriáceos, discolores. Inflorescencias 3-4 veces compuestas, de $12-16 \mathrm{~cm}$ de largo, $8-12 \mathrm{~cm}$ de ancho, pedúnculos de $2-15 \mathrm{~cm}$ de largo, con pubescencia de pelos estrellados, radios primarios 6-7, de 20-30 mm de largo, radios secundarios 4-6, pedicelos de 6-12 $\mathrm{mm}$ de largo, con 
pubescencia de pelos estrellados, bractéolas lanceoladas, de 8-16 mm de largo, usualmente caedizas; cáliz cilíndrico a estrechamente campanulado, pubescencia estrellada, tubo de 1-2 mm de largo, lóbulos triangulares, de $0.6 \mathrm{~mm}$ de largo, sin cilios; corola campanulada, tubo de 1-2 mm de largo, lóbulos oblongos, extendidos, de 2-2.5 mm de largo, con pelos estrellados en la parte externa, blanco-cremosa; estambres de 3-4 mm de largo; estilo glabro. Frutos elipsoides, frecuentemente falcados, de 6-8 $\mathrm{mm}$ de largo, 5-7 $\mathrm{mm}$ de ancho, diminutamente pubescentes, negros; pirenos de 3-5 mm de largo, 2-3 $\mathrm{mm}$ de ancho, con surco central tenue.

Distribución y hábitat. En México se distribuye en el sur del país (Figura 4), extendiéndose hasta Guatemala. Crece en bosque mesófilo de montaña, en elevaciones de 1,300$1,800 \mathrm{~m}$. Florece de abril a junio. Elemento relativamente escaso en el país, vulnerable en algunas áreas donde habita.

Comentario taxonómico. La especie presenta amplia variación en las hojas que tienden más a la forma lanceolada, con nervios poco notorios, anastomosados hacia el margen y con distribución entre los 1300-1800 m de altitud (ver comentario en $V$. jucundum).

Ejemplares examinados. CHIAPAS: Mpio. Trinitaria,
Laguna Pojoj near lago Tsis kaw, Lagunas de Montebello National Park, Breedlove 37073 (ENCB); GUERRERO: Mpio. Coyuca de Catalán, Las Palancas, $14 \mathrm{~km}$ al N de las Humedas, González 6760 (MEXU), OAXACA: $12 \mathrm{~km}$ al N de Solá de Vega on the road to Oaxaca, Bartholomew 3269 (MEXU, NY); Mpio. Santiago Juxtlahuaca, Dto. Juxtlahuaca, $3.5 \mathrm{~km}$ de la desviación a San Juan Piñas, carretera a San Sebastián, Calzada 21473 (MEXU); Mpio. Coicoyán, Dto. Juxtlahuaca, ladera inmediatamente al $\mathrm{S}$ del pueblo de Coicoyán, De Avila 322 (MEXU); Mpio. Totontepec, Dto. Mixe, El Mirador, 4 km al W de Totontepec, Ramírez 498 (MEXU); Dto. Mixe, $11 \mathrm{~km}$ al NE de la desviación a Zacatepec, Torres 2722 (MEXU).

Viburnum elatum Benth., Pl. Hartw. 59. 1840. TIPO: México. Michoacán, Tlalpuxahua, may. 1830, G. J. Graham 220 (Holotipo: K000573720!; Isotipo: GH).

Viburnum densum Benth., Pl. Hartw. p. 59. 1840. TIPO: México. Hidalgo, Real del Monte, may. 1830, C. J. Graham 224 (Holotipo: K000573722!). 1933. V. cuneifolium Bartlett, Proc. Amer. Acad. Arts 44(21): 635. 1909. V. elatum Benth. var. cuneifolium (Bartlett) C.V.Morton, Contr. U.S. Nat. Herb. 26(7): 347. TIPO: México. Nuevo León, Sierra Madre above Monterrey, 27 mar. 1906, C. G. Pringle 10234 (Holotipo: GH; Isotipos: ASU, BM, CAS0004988!, E, F, K000573719!, MICH, MO, NY, P, US).

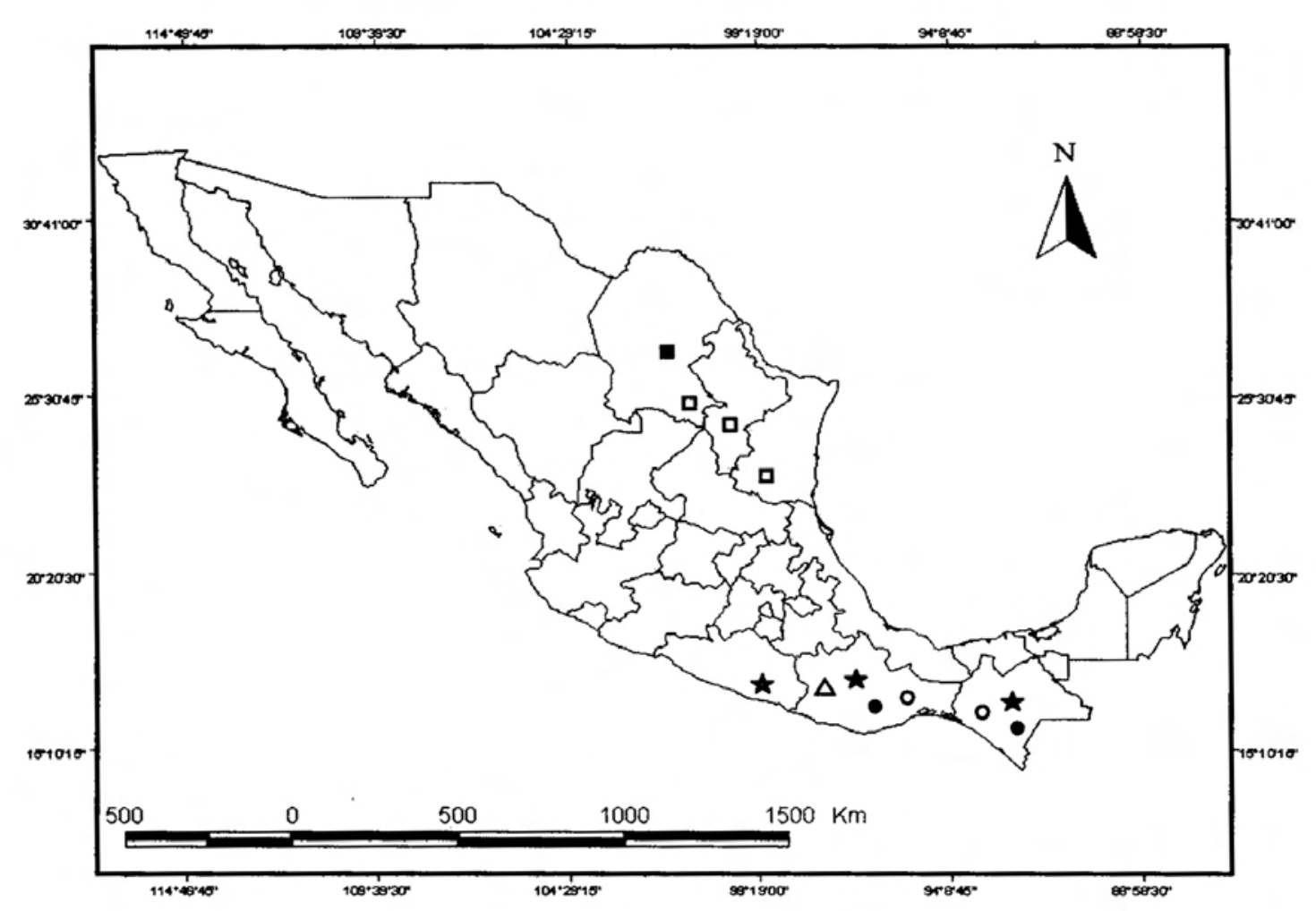

Figura 4. Distribución conocida en México de Viburnum discolor (círculos blancos), V. jucundum (círculos negros), V. disjunctum (estrellas), V. sulcatum (triángulo), V. rafinesquianum var. affine (cuadros blancos) y V. rufidulum (cuadro negro ). 
Arbustos o árboles de hasta $8 \mathrm{~m}$ de alto; ramas glabras. Hojas con estípulas cedizas, con pecíolos de 6-18 mm de largo, surcados, estrechamente alados, glabros, con puntos negros; limbos ovados a lanceolados, de 3-6 cm de largo, $1.5-3 \mathrm{~cm}$ de ancho, base cuneada, ápice agudo a obtuso, característicamente acuminado con la punta roma (embotada), margen entero a diminutamente serrulado, nervación poco conspicua, de 5-7 nervios laterales, curveados, con venación secundaria anastomosada, glabras, envés con puntos negros, subcoriáceos, concolores. Inflorescencias 3 veces compuestas, de 2.5-3.5 cm de largo, 5-7 cm de ancho, sin pedúnculos, radios primarios 4-5, de 1-2 $\mathrm{cm}$ de largo, radios secundarios de 7-10 $\mathrm{mm}$ de largo, glabros, con puntos negros, bractéolas lanceladas a subuladas, de 1-2 mm de largo; cáliz tubular, glabro, tubo cerca de $2 \mathrm{~mm}$ de largo, lóbulos redondeados, de 0.3- $0.6 \mathrm{~mm}$ de largo; corola rotada, tubo de 1-2 mm de largo, lóbulos oblongos de 2-2.5 mm de largo, glabra, blanca; estambres de 2-3 mm de largo; estilo glabro. Frutos elipsoides, ligeramente aplanados, de 8-12 mm de largo, 6-8 mm de ancho, glabros, rojos a púrpuras; pirenos de 5-7 mm de largo, 3-4 mm de ancho, sin estrías ni surco central.

Distribución y hábitat. Endémica de México, con amplia distribución en el país (Figura 3). Crece en laderas de cerros, cañadas, en bosques de pino-encino, pino piñonero, pino-cedro, mesófilo de montaña y vegetación de galería, en elevaciones de 1,400-3,000 m. Florece de marzo a mayo. Relativamente abundante en los lugares que habita, por lo que se considera que no tiene problemas de supervivencia. Usos y nombres comunes. Planta con uso en medicina tradicional en Chiapas. Localmente conocida en tzeltal como chenek 'te', kakaw wama, prijol te', tsajal tsop, y en español como pasilla.

Ejemplares examinados. CHIAPAS: Mpio. Teopisca, along Mexican hwy 190, 5 mi, NW of Teopisca, Breedlove 29512 (ENCB); Mpio. Zinacatlán, Buchol bo bajo, 2 km de Zinacatlán hacia el NE, carretera pavimentada, Girón 58 (ANSM); Mpio. San Cristóbal de las Casas, San Antonio Las RosasKóstik, Martínez 54 (IEB); Mpio. San Cristóbal de Las Casas, Cerro de Huitepec, Méndez 9190 (ENCB, TEX); Mpio. San Juan Chamula, Majo`Nut, Santiz 601 (ENCB, TEX); DISTRITO FEDERAL: Pedregal de San Ángel, cerca de Eslava, Espinosa 708 (ENCB, TEX); Rancho Pachita, Delegación Contreras, Ventura 2665 (ENCB); San Bartolo, Delegación Álvaro Obregón, Ventura 2705 (ENCB); DURANGO: Mpio. Mezquital, El Saucillo, $2.8 \mathrm{~km}$ al O, camino a Xoconoxtle, González 3706 (ANSM, IEB, MEXU); Mpio. Mezquital, Candelarita Chico, Solís 870 (ANSM, CIIDIR, MEXU), Solís 895 (ANSM, CIIDIR); GUANAJUATO: Mpio. San Luis de la Paz, 2 km al NW de Mesas de Jesús, sobre el camino a San Antón, Rzedowski 53039 (IEB); Mpio.
Santa Catarina, Mesa de Salinas, $10 \mathrm{~km}$ al NW de Molinitos, Ventura y López 6713 (ENCB, IEB, MEXU, XAL); Mpio. Xichú, San Miguel de las Casitas, Ventura y López 8698 (IEB); Mpio. Atarjea, El Arroyote, por Carricillo, Ventura y López 9134 (IEB, MEXU); HIDALGO: Mpio. Huasca, 16 $\mathrm{km}$ al S de Huasca, Hernández 5752 (ENCB); Mpio. Zimapán, alrededores de Verdozas, Huerta 1480 (MEXU, XAL); Mpio. El Chico, alrededores de El Chico, Medina 2057 (ENCB); Mpio. Huasca, $5 \mathrm{~km}$ al SSE de Huasca, camino a Ixtula-Zenbo, Medina y Barrios 3951 (ENCB, IEB); Mpio. Zimapán, barranca Piedra Angosta, Encarnación, Zamudio 13723 (IEB); JALISCO: Mpio. Mezquitic, $18 \mathrm{~km}$ pasando el Bajío del Tule hacia Bolaños, Cházaro 6578 (IEB); Mpio. Tecolotlán, Sierra de Quilla, travesía de a pie de La Ciénega a Puerta de Hierro, Cházaro 8097 (IEB); Mpio. Bolaños, 5 $\mathrm{km}$ al W de crucero Tuxpan de Bolaños-Los Amoles, Vanderitas, Flores 4600 (MEXU); Mpio. Tecolotlán, campamento La Ciénega Sierra de Quila, Machuca 8440 (IEB); steep pastured hills about $10 \mathrm{~km} \mathrm{NW}$ of San Miguel de la Sierra (40-50 km airline W of Ayutla), McVaugh 23490 (ENCB); MÉXICO: Mpio. Villa de San Nicolás Romero, $1 \mathrm{~km}$ al W de Magu, Rzedowski 16841 (ENCB); Mpio. Huxquilucan, entre Santa Cruz Ayotuxco y Dos Ríos, Rzedowski 22055 (ENCB, TEX); Mpio. Santa Ana Xilotzingo, $2 \mathrm{~km}$ al E de San Luis Ayucan, Rzedowski 22404 (ENCB); Mpio. Villa de Carbón, Tapia s.n. (ENCB); Mpio. Villa de San Nicolás Romero, San Pedro, Ventura 3288 (ENCB); MICHOACÁN: Mpio. Morelia, cercanías a Morelia, Arséne 5256 (MO, NY); Mpio. Nuevo Parangaricutiro, Cerro Tancítaro, 27 km al W de Uruapan, García 4588 (IEB); Mpio. Zinapécuaro, arroyo La Hierbabuena, al SW de la presa Laguna Larga, Jasso 960 (IEB); Mpio. Melchor Ocampo, El Salto, 7 km al E de Ocampo, Martínez 413 (ENCB, MEXU); Mpio. Morelia, $3 \mathrm{~km}$ al S de San Miguel del Monte, Rzedowski 53421 (MEXU); NAYARIT: Mpio. Jesús María, barranca $1.5 \mathrm{~km}$ al S de Santa Teresa del Nayar, Díaz Luna 9555 (ENCB, IEB); Mpio. Nayar, along the arroyo Santa Rosa, W of Santa Teresa, $100 \mathrm{~km}$ airline NNE of Tepic, Breedlove 44541 (MEXU); NUEVO LEÓN: Mpio. Zaragoza, La Encantada, Estrada 1995 (ANSM, CFNL); Mpio. San Pedro Garza García, Sierra Madre Oriental, limestone slopes of Chipinque, mesa SW of Monterrey, Webster 11212 (MEXU); QUERÉTARO: Mpio. Pinal de Amoles, $2 \mathrm{~km}$ al E de San Pedro El Viejo, Carranza 558 (ENCB, IEB, MEXU); Mpio. San Joaquín, ruinas Las Ranas, 2 km al N de San Joaquín, Fernández 3265 (ENCB, IEB, TEX); Mpio. Landa, Puerto del Arrastradero, $6 \mathrm{~km}$ al NE de Acactitlán de Zaragoza, González 1138 (ANSM, IEB); Mpio. San Joaquín, 17.5 km de Bucareli, por carretera a San Joaquín, Pérez 4477 (ANSM, IEB, MEXU); Mpio. San Joaquín, $13 \mathrm{~km}$ al NW de San Joaquín, Zamudio 7285 (ANSM, IEB); SAN LUÍS POTOSÍ: mountains about 10 miles NE of Ciudad del Maíz (17 mi. by road), McVaugh 10458 (MEXU, NY, TEX); SINALOA: Mpio. Badiraguato, 3 mi. $\mathrm{N}$ of Los Hornos along 
road to Ocurahul, Breedlove 18436 (ENCB); TAMAULIPAS: Mpio. Gómez Farías, Malpaís de la Perra, 30 km al NW del Rancho El Cielo, García 831 (ENCB); Mpio. Llera, Rancho El Julilo, 15 km al NW de Gómez Farías, González 10449 (MEXU); Mpio. Hidalgo, $5 \mathrm{~km}$ al N de Los Caballos, González 14103 (MEXU); Mpio. Quemes, 3 km al SW de Los Pedros, González 17304 (MEXU); Mpio. Hidalgo, road from Sta. Engracia toward Dulces Nombres, Nesom 7503 (ANSM, MEXU, TEX).

Viburnum hartwegii Benth., Pl. Hartw. 84. 1841. TIPO: Guatemala. Guatemala, Montañas de Santa María, cerca de la ciudad de Guatemala, 1840, K. T. Hartweg 580 (Holotipo: K 000573717 !; Isotipos: BM, BR, K000573718!, LD, NY, P).

Viburnum guatemalense Gand., Bull. Soc. Bot. France 65: 33. 1918. TIPO: Guatemala. Alta Verapaz, 21 ene. 1918, $H$. von Tuerckheim s. $n$. (Holotipo: C; Isotipo: von Tuerckheim 8489 NY00278612!).

Arbustos de 3-6 m de alto; ramas con pubescencia de pelos fasciculados, antrorsos, color amarillo-dorado. Hojas sin estípulas, con pecíolos de 6-16 mm de largo, ligeramente surcados, esparcidamente hirsútulos; limbos elípticos a lanceolados, de 5-15 cm de largo, 2-5 cm de ancho, base cuneada a redondeada, ápice acuminado-obtuso, margen entero, con 4-5 pares de nervios en el envés, no anastomosados, con pelos simples y fasciculados cortos, esparcidos o restringidos a la nerviación, haz y envés glabrescentes, subcoriáceos, ligeramente discolores, opacos. Inflorescencias 3 veces compuestas, de 4-6 cm de largo, 8-14 cm de ancho; pedúnculos de $2-4 \mathrm{~cm}$ de largo, hirsútulos, radios primarios 4-6, de 12-30 mm de largo, radios secundarios 4-6, de 10$18 \mathrm{~mm}$ de largo, pedicelos de 6-12 $\mathrm{mm}$ de largo, hirsútulos, bractéolas foliáceas, deciduas, de 8-16 mm de largo; cáliz cilíndrico a estrechamente campanulado, glabro a estrigoso, tubo de 1-2 mm de largo, lóbulos triangulares, de $c a .1 \mathrm{~mm}$ de largo, ciliados; corola rotada, tubo de 1-2 mm de largo, lóbulos oblongos, extendidos, de 2-2.5 mm de largo, con pubescencia estrigosa, blanca; estambres de $3 \mathrm{~mm}$ de largo; estilo glabro. Frutos casi esféricos, de 6-8 mm de largo, 5$7 \mathrm{~mm}$ de ancho, frecuentemente falcados, glabros, negros; pirenos elipsoides, de 4-7 $\mathrm{mm}$ de largo, 3-5 $\mathrm{mm}$ de ancho, surco central tenue.

Distribución y hábitat. Con distribución en el occidente y sur del país (Figura 3), extendiéndose a Guatemala, El Salvador, Honduras y Nicaragua. Crece en vegetación secundaria en bosque caducifolio, de niebla y selva baja perennifolia, en elevaciones de 1,400-2,500 m. Florece de abril a noviembre. Localmente es una planta común, con abundantes muestras colectadas, sin problemas de supervivencia.

Usos y nombres comunes. Planta reportada con uso en medi- cina tradicional en Chiapas. En tzeltal es localmente conocida como isop, isop-té, yaxjalabte, yaxal-isop, chikal-té y stop. En español como arrayancillo, chilpatillo y pimentilla.

Ejemplares examinados. CHIAPAS: Mpio. Arriaga, ejido López Mateos, Cerro El Carrizalillo, Alvarado 908 (MEXU); Mpio. Ocosingo, $10 \mathrm{~km} \mathrm{SW}$ of Ocosingo along road to San Cristóbal, Breedlove 27822 (ENCB); Mpio. San Andrés Larráinzar, paraje Talom' witz, Tierra Fría, a 1 km de la escuela, González 438 (IEB); Mpio. Amatengo del Valle, Pilaston $4 \mathrm{~km}$ al $\mathrm{N}$ de la cabecera municipal de Amatengo del Valle, López 75 (ENCB); Mpio. Altamirano, Puebla Nueva, Pérez 41 (ENCB); GUERRERO: Carrizo-Pie de la Cuesta, Hinton 14741 (ENCB, NY); JALISCO: Nevado de Colima, N slope below La Joya, Boutin 2344 (MEXU); Mpio. Autlán, Cañada El Laurelito, Cuevas 4578 (ENCB); Mpio: Ciudad Guzmán, camino de La Piedra Ancha hacia Cd. Guzmán, Negrete 11 (IEB, TEX); Mpio. Tolimán, 12$13 \mathrm{~km}$ al NE de Minatitlán, Santana 5207 (IEB); 0.6 km by main lumber road $\mathrm{N}$ of Cerro El Almela towards Estación Biológica Las Joyas, $13.5 \mathrm{~km}$ (by air) SSE of Ahuacapan, N slope ca. $18 \mathrm{~km}$ below the very crest of sierra de Manantlán, Wetter 1077 (ENCB, MEXU); OAXACA: Mpio. San Mateo Pinas, cerca del cementerio de San Pedro Cafetitlán, Acosta 1485 (IEB, MEXU); Mpio. Comaltepec, Dto. Ixtlán, 15 km al $\mathrm{N}$ de Comaltepec, Cedillo 620 (MEXU); Dto. Mixe, El Mirador, km 8 carretera Totontepec-Choapan, García 1309 (MEXU); Mpio. Santa María Chimalapa, camino Lázaro Cárdenas-Santa María Chimalapa, González 3798 (IBUG, IEB); Mpio. Totontepec, Dto. Mixe, atrás del Cerro de la Mitra, $6 \mathrm{~km}$ al W de Totontepec, Ramírez 76 (MEXU); Mpio. Totontepec, Dto. Coapan, $8.4 \mathrm{~km}$ al NE de Totontepec camino a Choapan, Torres 4004 (ENCB, MEXU); VERACRUZ: Mpio. Soteapan, Sierra de Santa Martha al NE de Ocotal Grande, Beaman 5453 (MEXU); Mpio. San Andrés Tuxtla, Volcán San Martín, INIF 43 (MEXU), Miranda 8347 (MEXU); Mpio. Zongolica, entre Zongolica y Nacaxtla, Vázquez 571 (IEB, MEXU, NY, XAL).

Viburnum jucundum C.V.Morton, Contr. U.S. Nat. Herb. 26(7): 355. 1933. TIPO: México. Chiapas, 1864-1870, A. B. Ghiesbreght 729 (Holotipo: GH00031668!).

Viburnum matudae C.V.Morton, Proc. Biol. Soc. Wash. 51: 215. 1938. TIPO: México. Chiapas, Siltepec, 9 ago. 1937, E. Matuda 1587 (Holotipo: US00139026!; Isotipos: B, LL, MEXU, MICH 1192100!). V. chiapense Lundell, Bull. Torrey Bot. Club 66(9): 603. 1939. TIPO: México. Chiapas, west side of Mt. Tacaná, 30 mar. 1939, E. Matuda 2925 (Holotipo: MICH 1192096!; Isotipos: F, K, NY, US).

Árboles de 3-6 m de alto; ramas con pubescencia densa amarillenta de pelos estrellados. Hojas sin estípulas, con pecíolos de 6-16 $\mathrm{mm}$ de largo, ligeramente surcados, con 
pubescencia de pelos simples o estrellados; limbos ovados, en ocasiones anchamente oblongos a casi circulares, de 5-14 cm de largo, 5-10 cm de ancho, base cuneada a redondeada, ápice acuminado, margen entero, frecuentemente serrulados en la base, o con dientecillos glandulares, con 3-5 pares de nervios curvados, no anastomosados, conspicuos en el envés, haz con pubescencia estrellada, envés con pubescencia densa estrellada amarillenta, subcoriáceos, discolores, opacos. Inflorescencias 4 veces compuestas, de 4-6 cm de largo, 8-12 cm de ancho; pedúnculos de $2-8 \mathrm{~cm}$ de largo, con pubescencia densa amarillenta de pelos estrellados, radios primarios 5-7, de 20$30 \mathrm{~mm}$ de largo, radios secundarios 4-6, de 10-18 mm de largo, pedicelos de 6-12 $\mathrm{mm}$ de largo, con pubescencia de pelos estrellados, bractéolas lanceoladas, deciduas de 8$16 \mathrm{~mm}$ de largo; cáliz cilíndrico a estrechamente campanulado, pubescencia estrellada, tubo de 1-2 mm de largo, lóbulos triangulares, de $0.6 \mathrm{~mm}$ de largo, sin cilios; corola campanulada, tubo de 2-3 mm de largo, lóbulos oblongos, extendidos, de 2-2.5 $\mathrm{mm}$ de largo, con pelos estrellados en la parte externa, blanco-cremosa; estambres de 3-4 mm de largo; estilo glabro. Frutos elipsoides, frecuentemente falcados, de 6-8 $\mathrm{mm}$ de largo, 5-7 $\mathrm{mm}$ de ancho, esparcidamente pubescentes, negros; pirenos elipsoides, de 3-5 mm de largo, 2-3 mm de ancho, con surco central tenue.

Distribución y hábitat. Se distribuye en el sur de México (Figura 4), además de Guatemala y El Salvador. Crece en bosques de encino y mesófilo de montaña, en elevaciones de 1,500-2,800 m. Florece de junio a octubre. Elemento relativamente abundante en el área, sin problemas de supervivencia en la actualidad.

Usos y nombres comunes. Se desconoce su uso. En tzeltal se le conoce localmente como isop, sakil tsop y sop-té.

Comentario taxonómico. La especie presenta hojas ovadas a casi circulares, con nervios conspicuos, que llegan hasta el margen y con distribución reportada hasta los 2,800 m de altitud.

Ejemplares examinados. CHIAPAS: Mpio. San Cristóbal de las Casas, $13 \mathrm{~km}$ al N de San Cristóbal de las Casas sobre el camino a Tenejapa, Cabrera 5711 (MEXU); Mpio. San Andrés Larraínzar, paraje Bachén, González 59 (IEB, TEX); Mpio. Siltepec, Ventana, near Siltepec, Matuda 4548 (NY, TEX); Mpio. Zinacantán, $2 \mathrm{~km}$ de Chainatic viniendo de Navenchauc, Ramírez 550 (ENCB); OAXACA: Dto. Villa Alta, $3 \mathrm{~km}$ al $\mathrm{S}$ de la desviación a Juquilla, camino a Talea, Cedillo 2381 (MEXU); Mpio. San Felipe Usila, cerca del Río Perfume, ladera W, 8 km en línea recta al S de Santa Cruz Tepetotula, Meave 1632 (MEXU); Mpio. San Juan Chamula, paraje Jobien ton, Santiz 867 (ENCB); Mpio. San Jerónimo Coatlán, Dto. Miahuatlán, Espuelas de San Antonio, $13.5 \mathrm{~km}$ al SW de San Jerónimo Coatlán, brecha a
Piedra Larga, Toríz 929 (MEXU); Dto. Villa Alta, 6 km al N del entronque Mixistlán-Totontepec, hacia San Andrés Yaa, Torres 487 (MEXU).

Viburnum loeseneri Graebn., Fedde Repert. Sp. Nov. 12: 244. 1913. TIPO: México. C. A. Ehrenberg s. n. (Holotipo: B (destruido); fototipo: F017817!); México. Michoacán, $C$. G. Ehrenberg s. n. (sintipo: US).

Arbustos o árboles de 3-8 m de alto; ramas con pubescencia estrellada, glabrescentes en la madurez. Hojas con estípulas caedizas, con pecíolos de 4-8 mm de largo, ligeramente o no surcados, con pelos estrellados; limbos ovados, de 3-5(-8) $\mathrm{cm}$ de largo, 2-4 $\mathrm{cm}$ de ancho, base redondeada, ápice agudo, margen entero a espaciadamente denticulado, con 3-4 pares de nervios poco conspicuos, curvados y anastomosados, haz esparcidamente estrigoso, envés con pubescencia estrellada esparcida, membranáceos, discolores. Inflorescencias 2-3 veces compuestas, de $2-4 \mathrm{~cm}$ de largo y $2-5 \mathrm{~cm}$ de ancho; pedúnculos de $2-4 \mathrm{~cm}$ de largo, pubescencia estrellada, radios primarios 4-6, de 3-8 $\mathrm{mm}$ de largo, radios secundarios 4-6, de 2-4 mm de largo, pedicelos de 6-12 $\mathrm{mm}$ de largo, pubescencia estrellada, bractéolas lineares, deciduas, de 3-5 mm de largo; cáliz tubular, con pubescencia estrellada y/o de pelos glandulares, tubo de $1.5 \mathrm{~mm}$ de largo, lóbulos triangulares, de $0.5-0.8 \mathrm{~mm}$ de largo, ciliados; corola campanulada, tubo de $2-3 \mathrm{~mm}$ de largo, lóbulos oblongos, extendidos, de 2-2.5 mm de largo, con pubescencia estrellada, blanca, raramente con tintes rosados; estambres 2-2.5 mm de largo; estilo glabro. Frutos casi elipsoides, de 5-9 $\mathrm{mm}$ de largo, 4-6 $\mathrm{mm}$ de ancho, glabros, negros; pirenos de 3-6 mm de largo, 2-4 mm de ancho, con surco central.

Distribución y hábitat. Endémica de México, con distribución en el occidente, centro y sur del país (Figura 5). Crece en laderas de cerros, cañadas y orilla de caminos, en bosques de pino-encino, pino-cedro y mesófilo de montaña, en elevaciones de 1,500-3,000 m. Florece de marzo a septiembre. Relativamente abundante en los lugares que habita, sin problema de supervivencia en la actualidad.

Usos y nombres comunes. Se desconoce su uso. En tzeltal se le conoce como tsop y tsop té.

Comentario taxonómico. Los ejemplares de Chiapas presentan inflorescencias más desarrolladas, en ocasiones de hasta $8 \mathrm{~cm}$ de ancho y el cáliz con abundantes pelos estrellados. Los de Oaxaca tienen hojas de mayor tamaño e inflorescencias con abundantes pelos glandulares rojizos. La densidad de la pubescencia presenta fuerte variación, tanto entre plantas como partes de un mismo individuo.

Ejemplares examinados. CHIAPAS: Mpio. Chamula, Kruz Ch'ot, 500 m al S de la escuela Cruz Ch'ot, Cruz 105 
(ANSM); Mpio. Oxchuc, Lelenchij, $850 \mathrm{~m}$ al E de la escuela Lelenchij, Meza 271 (ANSM); GUERRERO: Mpio. Taxco de Alarcón, $6.68 \mathrm{~km}$ al NW de Taxco, Durán 8612 (MEXU); JALISCO: Mpio. Tapalpa, después de cañada Las Ánimas al N del DIF, Huerta 97 (IEB); MÉXICO: Valle de Bravo, Boege 1800 (MEXU); Villa de Allende, Matuda 26809 (MEXU); MICHOACÁN: Mpio. Morelia, al SW de Atécuaro, Carranza 4071 (IEB); Mpio. Acuitzio, Cerro El Zopilote, Díaz 1448 (ENCB, IEB); Mpio. Santa Clara del Cobre, ejido Casas Blancas, Escobedo 1036 (ENCB, IEB, MEXU); Mpio. Los Reyes, Sicuicho, $1.5 \mathrm{~km}$ al NW del pueblo, Martínez 27 (IEB); Mpio. Cherán, 2 km al N de Cheranatzacuri, sobre la carretera a Carapan, Zamudio 5215 (ENCB, IEB, MEXU); OAXACA: Dto. Teposcolula. Mpio. Nicananduta, $13 \mathrm{~km}$ de Santiago Yolomécatl, carretera de terracería rumbo a Nicananduta, Calzada 23674 (MEXU); Mpio. Yolomécatl, $5 \mathrm{~km}$ de Yolomécatl, sobre la carretera de terracería rumbo a Nicananduta, Calzada 23898 (MEXU).

Viburnum membranaceum (Oerst.) Hemsl., Biol. Centr. Amer. Bot. 2: 2. 1881. Oreinotinus membranaceus Oerst., Vidensk. Medel. Dansk Naturhist. Foren. Kjöbenhavn 1860: 284. 1861. TIPO: México. Oaxaca, Cuesta de San Juan, may. 1842, F. M. Liebmann 7813 (Holotipo: C10009079!; Isotipo: C10009080!).
Viburnum macdougallii Matuda, Anales Inst. Biol. Univ. Nac. México 27(2): 370. 1956. TIPO: México. Oaxaca, San Andrés Chicahuastla del Cerro de Larión, 29 mar. 1954, T. MacDougall s. n. (Holotipo: MEXU! visto en publicación).

Arbustos o árboles de 4-8 m alto; ramas con pelos estrellados, glabrescentes. Hojas con estípulas caedizas, con pecíolos 8-20 mm largo, con pelos estrellados esparcidos, ligeramente surcados; limbos rómbicos a ovados, de $4-9 \mathrm{~cm}$ de largo, 2-6 cm de ancho, base redondeada a ligeramente cordada o cuneada, ápice acuminado, margen dentado, cada diente terminando en un mucrón glandular correspondiente a la terminación de cada nervio, nervios usualmente 5 pares, no anastomosados, conspicuos en el envés, pubescencia de pelos simples a estrellados, con pocos radios en el haz, más abundantes en el envés, usualmente restringidos a la nervación y en grupos en las axilas de los nervios secundarios, membranáceos, ligeramente discolores. Inflorescencias 1-2 veces compuestas, $3-4 \mathrm{~cm}$ de largo y $4-6 \mathrm{~cm}$ de ancho, pedúnculos 2-7 cm de largo, con pelos estrellados y glandulares radios primarios $5-6,1-3 \mathrm{~cm}$ de largo, radios secundarios 4-6, 6-16 mm de largo, pedicelos de 1-4 mm de largo, con pelos estrellados escasos y pelos glandulares, bractéolas lineares, 3-4 mm de largo, ciliadas; cáliz cilíndri-

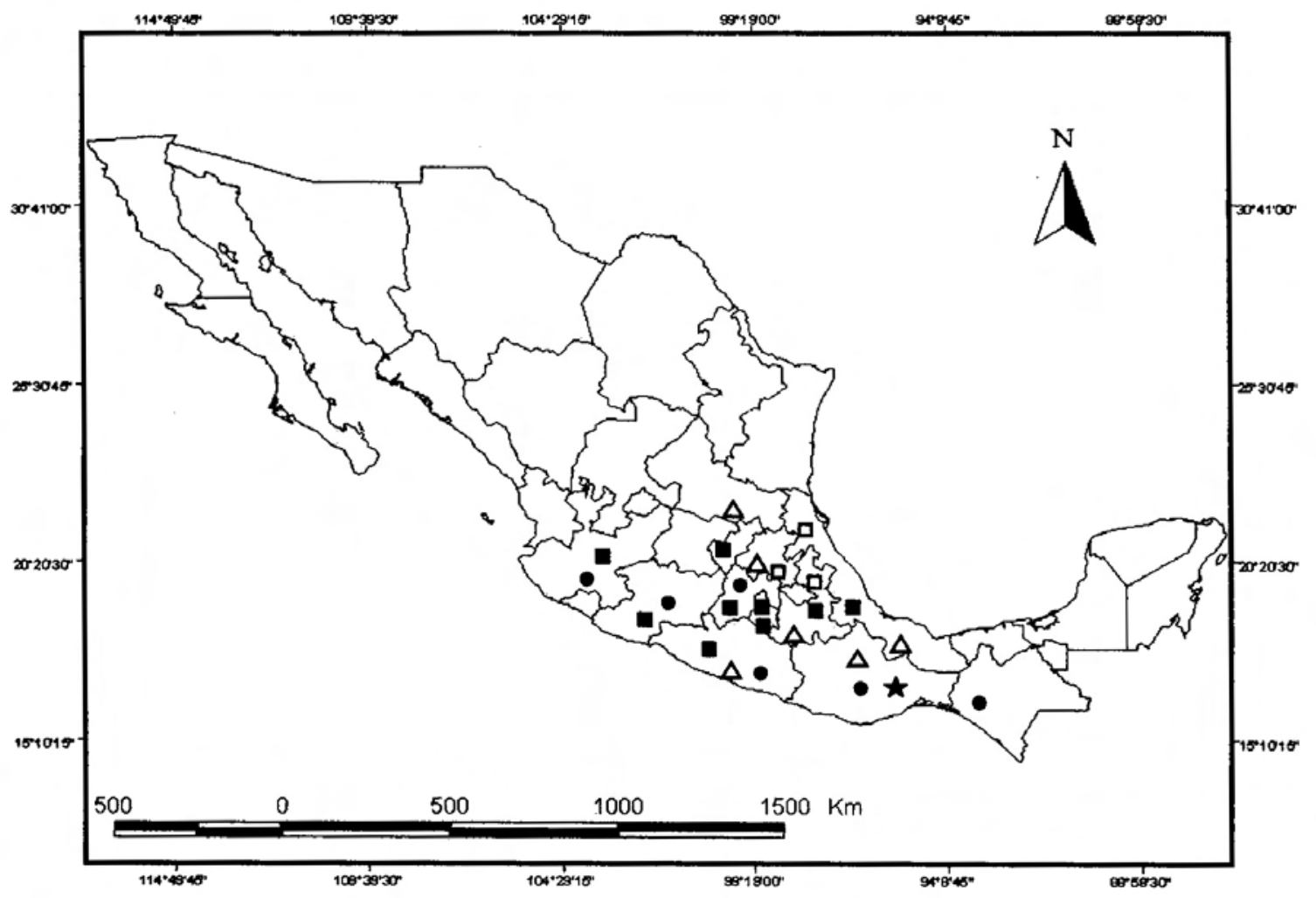

Figura 5. Distribución conocida en México de V. loeseneri (círculos negros), V. membranaceum (estrella), V. microcarpum (cuadros blancos), V. stenocalyx (cuadros negros) y V. tiliifolium (triángulos). 
co a estrechamente campanulado, glabro o con pocos pelos glandulares, tubo 1-2 mm de largo, lóbulos triangulares, $c a$. $1 \mathrm{~mm}$ de largo, usualmente sin cilios; corola rotada, tubo de 1-2 mm de largo, lóbulos oblongos, extendidos, de 2$2.5 \mathrm{~mm}$ de largo, glabra, blanca; estambres $3 \mathrm{~mm}$ de largo; estilo pubescente. Frutos elipsoides, bilobados, ligeramente aplanados, 3-4 mm de largo, 2-3 $\mathrm{mm}$ de ancho, glabros, negros; pirenos 2-3 mm de largo, 1-2 $\mathrm{mm}$ de ancho, con surco central (Figura 6).

Distribución y hábitat. Endémica de México, solo conocida de Oaxaca (Figura 5). Crece en bosques de pino-encino y encino, en elevaciones de 1,800-2,300 m. Florece de abril a agosto. Planta rara, con pocos reportes de colecta, es considerada como vulnerable.

Ejemplares examinados. OAXACA: Mpio. Tlaxiaco, $10 \mathrm{~km}$ al N de San Andrés Chicahuaxtla, García 357 (IEB, MEXU); Dto. Cuicatlán. Mpio. San Pedro Jocotipac, Lomade Enmedio, al SE de San Pedro Jocotipac, Tenorio 18327 (MEXU).

Viburnum microcarpum Schltdl. \& Cham., Linnaea 5: 170-171. 1830. TIPO: México. Veracruz, inter Jalapam et San Miguel del Soldado, C. J. W. Schiede \& F. Deppe “398" (Holotipo: G; Isotipos: BR0000006985974!, GOET, P00644615. Oreinotinus microcarpum (Schltdl. \& Cham.) Oerst., Vidensk. Meddel. Dansk Naturhist. Foren. Kjobenhavn 1860: 282. 1861. V. microcarpum Schltdl. \& Cham. var. evanescens Greenm., Proc. Amer. Acad. Arts 35: 313. 1900. TIPO: México. Veracruz, San Miguel del Soldado, 20 abr. 1899, C. G. Pringle 8172 (Holotipo: GH; Isotipos: C, BM, E, GOET, PH, SI001235!, US).

Arbustos o árboles de 3-8 m de alto; ramas con pubescencia estrellada blanquecina, glabras en la madurez. Hojas sin estípulas, con pecíolos de 1-2 cm de largo, con pelos estrellados; limbos oblongos, rómbicos, ovados a suborbiculares, de 5-12 cm de largo, 3-10 cm de ancho, base redondeada, cordada, a ligeramente cuneada, ápice agudo, acuminado, margen dentado-glandular, correspondiendo a la terminación de cada nervio, con 6-8 pares de nervios no anastomosados, conspicuos en el envés, haz de color verde oscuro, glabro, envés con densa pubescencia blanca de pelos estrellados y glándulas sésiles, membranáceos, fuertemente discolores. Inflorescencias 3 veces compuestas, de 4-6 cm de largo, 6$10 \mathrm{~cm}$ de ancho; pedúnculos de 1-4 $\mathrm{cm}$ de largo, con pelos estrellados, radios primarios 5-7, de 2-3 cm de largo, radios secundarios 4-6, de 10-18 mm de largo, pedicelos de 1-6 mm de largo, con abundantes pelos estrellados, bractéolas lineares, de 4-5 mm de largo; cáliz cilíndrico a estrechamente campanulado, glabro a espaciadamente glandular, tubo de 2-3 mm de largo, lóbulos triangulares, de $c a$. $1 \mathrm{~mm}$ de largo, sin cilios; corola rotada, tubo de 1-1.5 mm de largo, lóbu- los oblongos, extendidos, de 1.5-2 mm de largo, con pelos estrellados escasos y pelos glandulares, glabra, blanca a ligeramente rosada (rojiza en algunos ejemplares de herbario); estambres de $c a$. de $3 \mathrm{~mm}$ de largo; estilo pubescente. Frutos elipsoides, bilobados, de 3-4 $\mathrm{mm}$ de largo, 2-3 mm de ancho, glabros, negros; pirenos elipsoides, de 2-3 $\mathrm{mm}$ de largo, 1-2.2 mm de ancho, con surco central.

Distribución y hábitat. Endémica de México, con distribución en el oriente del país (Figura 5). Crece en vegetación secundaria y primaria de bosques caducifolios, de pino, pino-encino y encinar, en elevaciones de 900-2,800 m. Florece casi todo el año. Relativamente abundante en el área de distribución, sin problemas de supervivencia en la actualidad.

Usos y nombre común. Se desconoce su uso. Localmente conocida como negro.

Ejemplares examinados. HIDALGO: Mpio. Acaxochitlan, San Francisco, Villa 260 (IEB, MEXU); Mpio. Tenango de Doria, por el camino a Santa María, Gimate 584 (ENCB, TEX); Mpio. Zacualtipan, $5 \mathrm{~km}$ al SE de Zacualtipan, González 4927 (MEXU); Mpio. Tenango de Doria, $2 \mathrm{~km}$ al $\mathrm{N}$ de Tenango de Doria hacia al Bosco, Hernández 4216 (ENCB, MEXU); Mpio. Tlanchinol, Olotla, aprox. $3 \mathrm{~km}$ delante de Olotla, Luna 259 (MEXU); Mpio. Tenango de Doria, El Damo, $2 \mathrm{~km}$ al SE de Tenango de Doria, desviación a San Nicolás, Luna 867 (MEXU); PUEBLA: Mpio. Pahuatlán, Xopanapa, $8 \mathrm{~km}$ al SW de Pahuatlán, Campos 227 (MEXU); Mpio. Huachinango, Río Texcapa, Puig 4809 (ENCB); Mpio. Zacapoaxtla, arroyo Tenaxatena al W de Apulca, Tenorio 8677 (MEXU, TEX); Mpio. Huachinango, Lomo Sierra al SE de Tepehuaquila, camino de Herradura a Zacatepec, Toriz 391 (MEXU); Mpio. Teziutlán, Las Coles, Ventura 17533 (ENCB, IEB, MEXU); VERACRUZ: Mpio. Alto Lucero, Rancho Nuevo, entre Plan de Las Hayas y Tierra Blanca, Castillo y Vázquez 1330 (XAL, TEX); Mpio. Acajete, cerca de Acajete, Cházaro 2141 (MEXU, XAL); Mpio. Las Minas, vereda por la hidroeléctrica hacia Rinconada, Duran y Narave 342 (IEB, MEXU, XAL); Mpio. Tlacolulan, $5 \mathrm{~km}$ después de Loma de Tablas, camino a Tlacolulan, Ortega 466 (IEB, NY, XAL); Mpio. Banderilla, Piletas $2 \mathrm{~km}$ antes de llegar a Banderilla, carretera Perote-Xalapa, Zola 323 (ENCB, MEXU, NY, XAL).

Viburnum obtusatum D.N.Gibson, Phytologia 25(3): 114. 1973. TIPO: México. Chiapas, steep slopes with Quercus, on NE slope of Zontehuitz near summit, and on road from San Cristóbal de Las Casas to Tenepaja, 19 ene. 1965, D. E. Breedlove \& P. H. Raven 8118 (Holotipo: F0053209f!; Isotipos: CAS, LL, MICH, US00139030!).

Arbustos de 2-6 m de alto; ramas con pubescencia de pelos simples y pelos glandulares. Hojas con estípulas caedizas, 


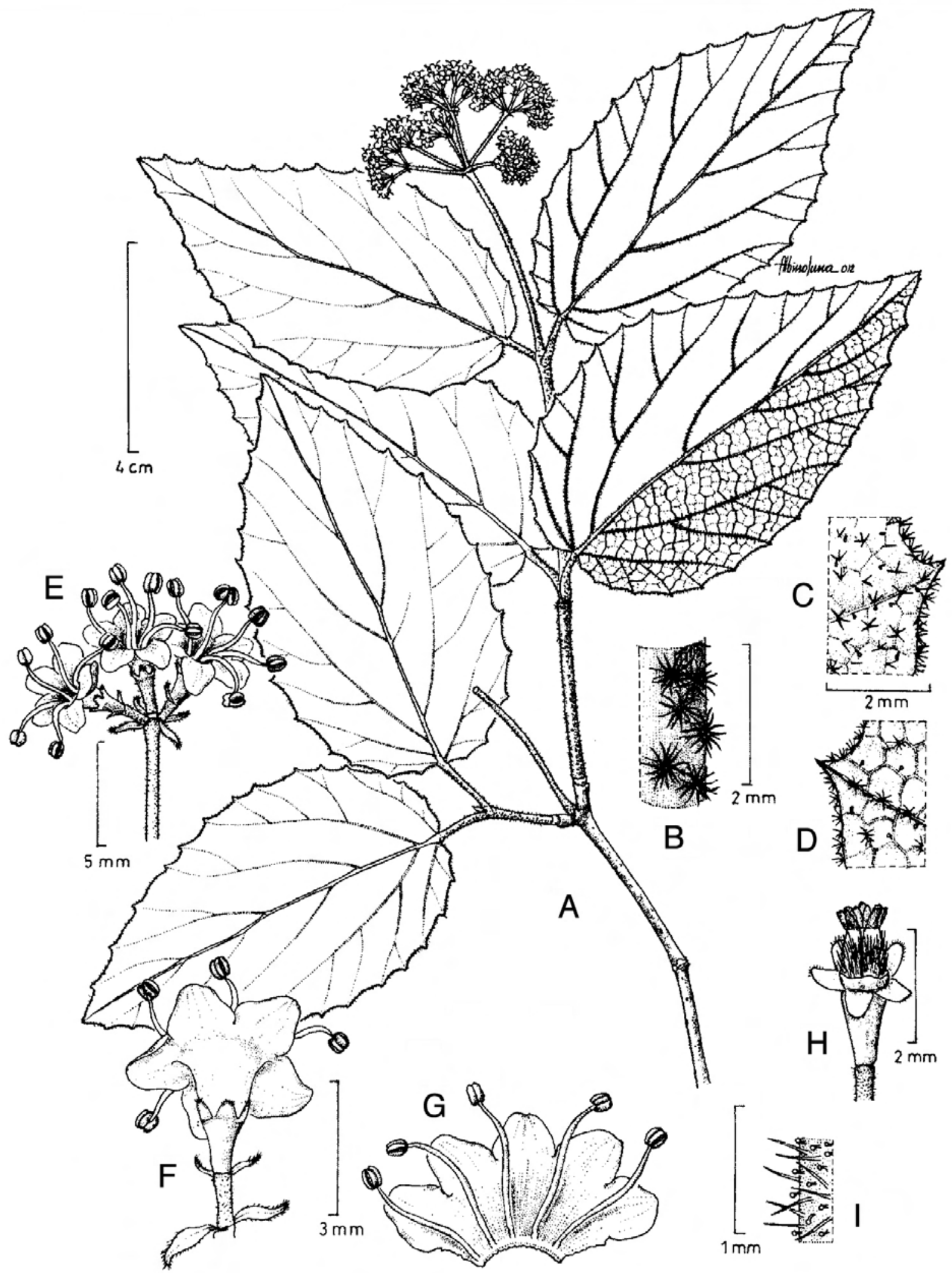

Figura 6. Viburnum membranaceum. A) Rama con hojas e inflorescencia. B) Detalle de la pubescencia de los tallos. C) Haz. D) Envés. E) Detalle de la inflorescencia. F). Flor. G). Corola y androceo. H). Cáliz y gineceo. I) Detalle de la pubescencia del pedicelo. Ilustrado por Albino Luna y reproducido de la Flora del Valle de Tehuacán-Cuicatlán 97: 5. 2012, con autorización del editor. 
con pecíolos de 4-12 $\mathrm{mm}$ de largo, ligeramente surcados, con pelos simples a glabrescentes; limbos ovados a lanceolados, de 2-6 cm de largo, 1-2 cm de ancho, base cuneada a redondeada, ápice acuminado-obtuso, margen entero, con 4-5 pares de nervios conspicuos en el envés, no anastomosados, con pelos simples y pelos glandulares, esparcidos o restringidos a la nerviación, glabrescente, de color verde brillante, membranáceos, ligeramente discolores. Inflorescencias 2 veces compuestas, de 2-4 cm de largo, 6-10 cm de ancho; pedúnculos de 2-3 cm de largo, con pubescencia glandular, radios primarios 5-7, de 10-25 mm de largo, radios secundarios 4-6, de 8-12 $\mathrm{mm}$ de largo, pedicelos de 4-10 mm de largo, con densa pubescencia glandular, bracteolas lanceoladas, deciduas, de 4-6 mm de largo; cáliz cilíndrico a estrechamente campanulado, glabro a estrigoso, tubo de 1-2 mm de largo, lóbulos triangulares, de $c a .1 \mathrm{~mm}$ de largo; corola rotada, tubo de 1-2 mm de largo, lóbulos oblongos, extendidos, de 2-2.5 mm de largo, estrigosa, blanca; estambres de $3 \mathrm{~mm}$ de largo; estilo glabro. Frutos casi esféricos, de 4-6 mm de largo, 3-5 mm de ancho, glabros, negros; pirenos elipsoides, 3-4 $\mathrm{mm}$ de largo, 2-3.5 $\mathrm{mm}$ de ancho, surco central poco notorio.

Distribución y hábitat. Endémica de México, con distribución en el sur del país (Figura 3). Crece en cañadas en bosques medianos, en elevaciones de 2,000-2,800 m. Florece de marzo a mayo. Por las pocas poblaciones conocidas, se considera a esta planta como vulnerable.

Ejemplares examinados. CHIAPAS: Mpio. San Cristóbal de las Casas, W side of Zontehuitz near Summit, Breedlove 53579 (ENCB, NY, TEX); Mpio. Chamula, Zontehuitz, Domínguez 65 (ANSM); OAXACA: Mpio. Eloxochitlán de Flores Magón, aprox. $200 \mathrm{~m}$ del Puente de Fierro, brecha a Puerto Rosete, Munn-Estrada 1400 (MEXU), 1402 (MEXU).

Viburnum rafinesquianum Schult., var. affine (Bush ex C.K.Schneid.) House, Torreya 35: 126. 1935. V. affine Bush ex C.K.Schneid., Ilustr. Handb. Laubh. 2(10): 649. 1911. TIPO: Estados Unidos. Missouri, Swan, B. F. Bush 776 (Holotipo: MO00151953!).

Viburnum australe C.V.Morton, Contr. U.S. Nat. Herb. 26(7): 346. 1933. TIPO: México. Nuevo León, Sierra Madre above Monterrey, 25 abr. 1906, C.G. Pringle 10193 (Holotipo: US; Isotipos: E00414156!, F, K000573723!, LL, MO).

Arbustos de 1-3 m de alto; ramas glabras a esparcidamente cubiertas con pelos glandulares rojizos. Hojas con estípulas adnadas a los pecíolos, pecíolos de $5-15 \mathrm{~mm}$ de largo, ligeramente surcados, casi planos, con pelos glandulares; limbos oblongos a deltoideo-ovados, de 3-8 $\mathrm{cm}$ de largo, 2-6 cm de ancho, base redondeada a cordada, ápice agudo, margen dentado-glandular, ciliado, con 3-6 pares de nervios conspicuos en el envés, rectos hasta el margen, no anastomosados, pubescencia de pelos simples y fasciculados, glándulas rojizas, esparcida en él haz, más densa en el envés, principalmente en las venas, membranáceos, discolores. Inflorescencias 2 veces compuestas de 4-6 cm de largo, 5-7 cm de ancho; pedúnculos de 1-5 cm de largo, con pubescencia glandular rojiza, radios primarios 5-7, de 2-3 $\mathrm{cm}$ de largo, radios secundarios 4-6, de 10-16 mm de largo, pedicelos de 6-8 $\mathrm{mm}$ de largo, con abundante pubescencia glandular rojiza, bractéolas lineares, de 4-6 mm de largo; cáliz estrechamente campanulado, glabro a esparcidamente glandular, tubo de $c a .2 \mathrm{~mm}$ de largo, lóbulos triangulares, de $c a .1 \mathrm{~mm}$ de largo, sin cilios; corola rotada, tubo de 1-1.5 $\mathrm{mm}$ de largo, lóbulos oblongos, extendidos, de 1.5-2 mm de largo, glabra, blanca (rojiza en ejemplares herborizados); estambres de $c a$. de $3 \mathrm{~mm}$ de largo; estilo pubescente. Frutos elipsoides, aplanados, sin surco central, de 7-12 mm de largo, 6-9 mm de ancho, glabros, negros; pireno elipsoide, 5-10 $\mathrm{mm}$ de largo, 3-5 $\mathrm{mm}$ de ancho, con tres estrías en un lado y dos en el otro.

Distribución y hábitat. Con distribución en Estados Unidos y Canadá, extendiéndose hasta el noreste de México (Figura 4). Crece en cañones y laderas húmedas en bosques de pino-oyamel, pino-encino y de piñoneros, en elevaciones de 1,800-2,800 m. Florece de abril a junio. Planta escasa en el área de distribución.

Ejemplares examinados. COAHUILA: Mpio. Acuña, Sierra Maderas del Carmen, Rancho El Secadero, Cañón Poblano, Carranza 2064 (ANSM, MEXU); Mpio. Acuña, Cañón Hundido, N side of Pico El Centinela, Sierra del Jardín, 8 km E of Rancho El Jardín, by winding road, Johnston 11771 (NY, TEX) Mpio. Acuña, Serranías del Burro, Rancho El Bonito, Riskind 2219 (ANSM, MEXU); Mpio. Arteaga, Cañón de Jame, $20 \mathrm{~km}$ al NE de la carretera Nacional (57), Villarreal 3121 (ANSM, ENCB); NUEVO LEÓN: Mpio. Galeana, El Orito, Hinton 18683 (ANSM, ENCB, MEXU); Mpio. San Pedro Garza García, Sierra Madre above Monterrey, Pringle 10193 (MEXU); TAMAULIPAS: Cerro Carrizo, vic. San José, Bartlett 10510 (NY).

Viburnum rufidulum Raf. Alsogr. Amer. 56. 1838. Tipo: Estados Unidos. jul. 1835, G. Engelmann s. n. (Holotipo: PH00028941!).

Viburnum. prunifolium L. var. ferrugineum Torr. \& A.Gray, Fl. N. Amer. 2: 15. 1841. V. ferrugineum (Torr. \& A.Gray) Small, Mem. Torrey Bot, Club 4(28): 128. 1894. TIPO: el mismo que V. rufidulum. V. rufotomentosum Small, Bull. Torrey Bot. Club 23: 410. 1896. Tipo: el mismo de V. rufidulum.

Arbustos o árboles pequeños hasta $10 \mathrm{~m}$ de alto; ramas con 
pubescencia estrellada, glabrescentes en la madurez. Hojas sin estípulas, con pecíolos de 5-20 mm de largo, casi planos, frecuentemente alados y con pubescencia estrellada; limbos elípticos a obovados, de 3-8 cm de largo, 2-4 cm de ancho, base cuneada a redondeada, ápice agudo a redondeado, margen serrulado, ciliado, con 3-6 pares de nervios curveados, con venación secundaria anastomosada, verde lustroso, glabros en el haz y con pubescencia estrellada en el envés, subcoriáceos, ligeramente discolores. Inflorescencias 3 veces compuestas, de 5-7 cm de largo, 4-11 cm de ancho; sésiles o en pedúnculos de hasta $1 \mathrm{~cm}$ de largo, radios primarios (2)34, de 2-3 cm de largo, radios secundarios 4-6, de 10-16 mm de largo, pedicelos de 6-8 $\mathrm{mm}$ de largo, con pubescencia estrellada rojiza a glabros, bractéolas lineares, de 3-5 mm de largo; cáliz estrechamente campanulado, glabro, tubo de ca. $2 \mathrm{~mm}$ de largo, lóbulos triangulares, de $c a .1 \mathrm{~mm}$ de largo, pubescentes; corola rotada, tubo de 1-1.5 mm de largo, lóbulos oblongos, extendidos, de 1.5-2 mm de largo, glabra, blanca a rosada; estambres de $c a$. de $3 \mathrm{~mm}$ de largo; estilo glabro. Frutos elipsoides, sin surco central, de 9-15 mm de largo, 7-10 mm de ancho, glabros, azul-oscuros; pirenos elipsoides, 7-12 $\mathrm{mm}$ de largo, 5-8 $\mathrm{mm}$ de ancho, sin estrías ni surco central.

Distribución y hábitat. Con distribución en los Estados Unidos extendiéndose al norte y centro de Coahuila (Figura 4). Crece en laderas en bosques de encino y pino-oyamel, en elevaciones de 1,300-2,000 m. Florece de marzo a mayo. Planta rara en el país, con distribución restringida al norte de Coahuila, muy escasa.

Ejemplares examinados. COAHUILA: Mpio. Múzquiz, Cañón Rincón de María, Sierra de La Babia, $28^{\circ} 27^{\prime}$ N, $102^{\circ} 04^{\prime}$ W, Carranza 3074 (ANSM, ENCB, TEX); Villarreal 8771 (ANSM).

Viburnum stenocalyx (Oerst.) Hemsl., Biol. Centr. Amer. Bot. 2: 3. 1881. Oreinotinus stenocalyx Oerst., Videsk. Meddel. Dansk Naturhist. Foren. Kjöbenhavn. 1860: 285. 1861. TIPO: México. Sin localidad precisa, C. A. Ehrenberg s. n. (Holotipo: C10009086!).

Viburnum stellatum (Oerst.) Hemsl., Biol. Centr. Amer. Bot. 2: 3. 1881. Oreinotinus stellatus Oerst., Vidensk. Meddel. Dansk Naturhist. Foren. Kjöbenhavn 1860: 292. 1861. TIPO: México. Veracruz, Pico de Orizaba, sep. 1841, F. M. Liebmann 7806 (Holotipo: C 10009084!).

Arbustos o árboles de 2-6 m de alto; ramas cubiertas por pubescencia densa estrellada, glabrescentes al madurar. Hojas sin estípulas, con pecíolos de 4-10 mm de largo, surcados, con abundantes pelos simples y estrellados; limbos ovados a lanceolados, de 5-10 cm de largo, $3-5 \mathrm{~cm}$ de ancho, base redondeada, ápice acuminado, margen dentado a denticulado, con dientes mucronados, ciliado, con 5-7 pares de nervios conspicuos, curvados, alcanzando el margen, no anastomosados, con pelos simples a estrellados esparcidos en el haz y más densos en el envés, o restringidos a los nervios, membranáceos, discolores. Inflorescencias 2-4 veces compuestas, de 3-5 cm de largo, 5-12 cm de ancho; pedúnculos de $1.5-2.5 \mathrm{~cm}$ de largo, con pelos estrellados y glandulares, radios primarios 5-7, de $15-30 \mathrm{~mm}$ de largo, radios secundarios 4-6, de 4-12 $\mathrm{mm}$ de largo, pedicelos de 6-8 $\mathrm{mm}$ de largo, con abundante pubescencia estrellada y pelos glandulares, bractéolas oblanceoladas, de 6-20 mm de largo; cáliz tubular, glabro o con pelos glandulares, tubo de 1.5-2 mm de largo, lóbulos oblongos, de 1-1.8 mm de largo, ciliados; corola campanulada, tubo de 1-1.5 mm de largo, lóbulos oblongos, extendidos, de 1.5-2 $\mathrm{mm}$ de largo, glabra, blanca; estambres de $2 \mathrm{~mm}$ de largo; estilo pubescente. Frutos elipsoides, bilobados, de 4-6 mm de largo, 2-4 mm de ancho, glabros, negros; pirenos elipsoides, de 4-6 $\mathrm{mm}$ de largo, 2-4 mm de ancho, con surco central.

Distribución y hábitat. Endémica de México, con distribución en el occidente, centro y oriente del país (Figura 5). Crece en laderas de cerros y cañadas en bosques mesófilos de montaña y pino-encino, en elevaciones de 2,300-2,800 m. Florece de marzo a julio. Planta escasa en algunas áreas y frecuente en otras, al parecer sin problemas fuertes de supervivencia.

Comentario taxonómico. Viburnum stellatum es reportado para Veracruz (Morton, 1933); sin embargo, al parecer no se ha vuelto a colectar. La revisión del tipo y ejemplares colectados por Pringle para el Distrito Federal, determinados con este nombre, muestran mucha similitud con V. stenocalyx. Esta especie parece estar relacionada con V. membranaceum, al presentar ambos características similares en la forma, textura membranácea y margen ciliado de la hoja, diferenciándose por la densidad de la pubescencia, nervación de la hoja, tamaño del fruto y distribución.

Ejemplares examinados. DISTRITO FEDERAL: Cañada de Contreras entre el tercer dínamo y la caja de agua, Espinosa 705 (ENCB, TEX); Delegación Magdalena Contreras, Cañada Contreras cerca del primer dínamo, Rivera 3660 (MEXU); Desierto de Los Leones, Valle de Las Monjas, Rzedowski 27223 (ENCB, TEX); Delegación Álvaro Obregón, sector Limbo, Ventura 2667 (ENCB); GUERRERO: Mpio. Coyuca de Catalán, Las Palmas, $65 \mathrm{~km}$ al NE de Pentatlán, González 6613 (MEXU); JALISCO: Mpio. Tecatitlán, carretera Ciudad Guzmán-Pihuamo, brecha a Llanitos, Morones 64 (CHAPA, IEB); MÉXICO: Mpio. Tlalmanalco, Cañada de Los Diamantes, $3 \mathrm{~km}$ al E de San Rafael, Cisneros 2434 (ENCB); Mpio. Tlalmanalco, 3 km al E de San Rafael, vertiente W del Ixtacihuatl, Rzedowski 19852 (ENCB); Mpio. Amecameca, cañada al NE de Chal- 
ma, Rzedowski 27191 (ENCB); Mpio. Amecameca, $7 \mathrm{~km}$ al E de Amecameca, cañada en la entrada del Cerro Venacho, Vargas 898 (ENCB); MICHOACÁN: Mpio. Morelia, Cerro de Las Nalgas, Nicolás s. $n$. (US) citado por Morton (1933, p. 363); MORELOS: S slope of the Sierra de Ajusco, ca. $4 \mathrm{~km}$ E of Zempoala on road to Huitzilal, Ilits 233 (ENCB); QUERÉTARO: Mpio. San Joaquín, 13 km al NW de San Joaquín, por el camino a Bucareli, Zamudio 7295 (ANSM, IEB, MEXU); VERACRUZ: Pico de Orizaba, Liebmann 7806 (C).

Viburnum sulcatum (Oerst.) Hemsl., Biol. Centr. Amer. Bot. 2: 3. 1881. Oreinotinus sulcatus Oerst., Vidensk. Meddel. Dansk Naturhist. Foren. Kjöbenhavn 1860: 287. 1861. TIPO: México. Oaxaca, Cerro de Zempoaltepec, jun. 1842, F. M. Liebmann s. n. (Holotipo: C10009087!; Isotipo: K000573707!).

Árboles de hasta $6 \mathrm{~m}$ de alto; ramas con pubescencia caféamarillenta de pelos estrellados. Hojas con estípulas caedizas, con pecíolos surcados, de 7-12 $\mathrm{mm}$ de largo, con abundantes pelos estrellados; limbos ovados, en ocasiones oblongos o elípticos, de 5-8 cm de largo, 3-5 cm de ancho, base redondeada a subcordada, ápice acuminado, margen entero, con 6-7 pares de nervios curvados, anastomosados hacia el margen, notorios en el envés, el haz glabro o con escasos pelos estrellados en la nervadura, el envés densamente cubierto por pubescencia estrellada amarillenta, membranáceos, discolores. Inflorescencias 3-4 veces compuestas, de 4-6 cm de largo, 3-6 cm de ancho; pedúnculos de 2-4 cm de largo, cubiertos por pelos estrellados, radios primarios 6-7, de 8-15 mm de largo, radios secundarios 4-6, de 10-18 mm de largo, pedicelos de 3-5 $\mathrm{mm}$ de largo, pubescencia densa de pelos estrellados amarillentos, bractéolas lineares, deciduas, de 3-6 mm de largo; cáliz cilíndrico, cubierto de pelos simples y glándulas rojizas, tubo de 1-2 mm de largo, lóbulos triangulares, de $0.6 \mathrm{~mm}$ de largo; corola campanulada, tubo de 1-2 mm de largo, lóbulos oblongos, extendidos, de 2-2.5 $\mathrm{mm}$ de largo, con pelos estrellados en la parte externa, blanca; estambres de 2.5-3.0 mm de largo; estilo glabro. Frutos elipsoides, frecuentemente falcados, de 6-8 $\mathrm{mm}$ de largo, 5$7 \mathrm{~mm}$ de ancho, esparcidamente pubescentes, negros; pirenos elipsoides de 3-5 mm de largo, con surco central tenue.

Distribución y hábitat. Endémica de México, con distribución en la vertiente del Pacifico de Oaxaca (Figura 4). Crece en bosque de pino y pino-encino, en elevaciones de 1,800-2,600 m. Florece de marzo a septiembre. Por su área limitada de distribución y escasa abundancia, es considerada como rara y vulnerable.

Ejemplares examinados. OAXACA: Pacific slope of mts. along road between Ixtlán and Valle Nacional, Breckon y Christman 664 (IEB); Dto. Ixtlán, Cerro Pelón, 30 km al N de Ixtlán, carretera Oaxaca-Tuxtepec, García 1866 (MEXU); Llano de las Flores, Sierra de Juárez, Miranda 9244 (MEXU); Mpio. Ixtlán de Juárez, Cerro Machín, Rzedowski 12436 (ENCB, IEB); Dto. Villa Alta, $11.7 \mathrm{~km}$ al N de Maravillas y $39.7 \mathrm{~km}$ al N Zoogocha, camino a Talea de Castro, Torres 2931 (MEXU).

Viburnum tiliifolium (Oerst.) Hemsl., Biol. Centr. Amer. Bot. 2: 3. 1881. Oreinotinus tiliaefolius Oerst., Nat. For. Kjöbenhavn Vid. Medd. 1860: 282. 1861. TIPO: México. Veracruz, entre Mirador y Jalapa, C. Sartorius s. $n$. (Holotipo: C12591736!).

Viburnum rhombifolium (Oerst.) Hemsl., Biol. Centr. Amer. Bot. 2: 3. 1881. Oreinotinus rhombifolius Oerst., Nat. For. Kjöbenhavn Vid. Medd. 1860: 283. 1861. TIPO: México. Veracruz, Mount Orizaba, 1840, H. G. Galeotti 2667 (Holotipo: W; Lectotipo: K000573696!, designado por Morton (1933)). Viburnum hirsutum C.V. Morton, Contr. U.S. Nat. Herb. 26 (7): 362. 1933. TIPO: México. Oaxaca, Cuicatlán, Cerro La Raya, 15 abr. 1919, C. Conzatti \& I. C. Gómez 3476 (Holotipo: US00139015!).

Arbustos o árboles de 3-10 m de alto, ramas con pubescencia densa estrellada, glabrescentes al madurar. Hojas con estípulas caedizas, con pecíolos de 1-2 cm de largo, cilíndricos a ligeramente acanalados, con abundantes pelos estrellados; limbos oblongos, rómbicos, ovados a suborbiculares, de 8-16 cm de largo, 4-12 $\mathrm{cm}$ de ancho, base redondeada a subcordada, ápice agudo, acuminado a caudado, margen sinuado dentado-glandular desde la base hasta el ápice, con 6-8 pares de nervios no anastomosados, conspicuos en el envés, pubescencia de pelos estrellados, con 2-8 ramas, muy denso en el envés, membranáceos, discolores. Inflorescencias 3 veces compuestas, de 4-6 $\mathrm{cm}$ de largo, 6-8 $\mathrm{cm}$ de ancho; pedúnculos de $1-5 \mathrm{~cm}$ de largo, cubiertos por pelos estrellados, radios primarios 5-6, de 2-3 cm de largo, radios secundarios 4-6, de 10-16 mm de largo, pedicelos de 6-8 mm de largo, con abundante pubescencia estrellada, bractéolas lineares, de 4-6 mm de largo; cáliz estrechamente campanulado, glabro a esparcidamente glandular, tubo de $c a .2 \mathrm{~mm}$ de largo, lóbulos triangulares, de $c a .1 \mathrm{~mm}$ de largo, sin cilios; corola rotada, tubo de 1-1.5 mm de largo, lóbulos oblongos, extendidos, de 1.5-2 mm de largo, glabra, blanca (rojiza en ejemplares herborizados); estambres de $c a$. de $3 \mathrm{~mm}$ de largo; estilo pubescente. Frutos elipsoides, bilobados, ligeramente aplanados, de 5-6 $\mathrm{mm}$ de largo, 3-4 $\mathrm{mm}$ de ancho, glabros, negros; pirenos de 3-4 $\mathrm{mm}$ de largo, 2-3 $\mathrm{mm}$ de ancho, con surco central.

Distribución y hábitat. Endémica de México, con distribución en el centro del país (Figura 5). Crece en bosques caducifolios, de pino, pino-oyamel, pino-encino, encinar y en vegetación secundaria derivada de estos, en eleva- 
ciones de 400-2,800 m. Florece de marzo a septiembre. Planta frecuente en el área de distribución, sin problemas de supervivencia.

Usos y nombres comunes. Se desconoce si tiene algún uso. En lengua náhuatl se le conoce localmente como ixtaxiwitl y en español como negro.

Ejemplares examinados. GUERRERO: Mpio. Coyuca de Catalán, Cerro del Chivo, $30 \mathrm{~km}$ al N de Palancas, González 6711 (ANSM, MEXU); HIDALGO: Mpio. Tenango de Doria, El Cirio, aprox. $2.8 \mathrm{~km}$ al E de El Damo, Alcántara 1123 (MEXU); Paraje El Hayal, ejido La Mojonera, $5 \mathrm{~km}$ SE de Zacualtipán, López 245 (ENCB, MEXU); Mpio. Zacualtipán, Tlahuelompa, 2 km al NW, Luna 2463 (MEXU); alrededores de Zacualtipán, Rzedowski 12504 (ENCB); Mpio. Acaxochitlán, San Francisco, Villa 219 (ENCB, IEB, MEXU); PUEBLA: Mpio. Hueyapan, $10 \mathrm{~km}$ al NE de Hueyapan, Contreras 5068 (MEXU); OAXACA: $8 \mathrm{~km}$ al SW de Huautla de Jiménez, hacia Teotitlán por el camino viejo que sale a Plan de Guadalupe, Torres 5038 (MEXU); SAN LUÍS POTOSÍ: Mpio. Xilitla, $5 \mathrm{~km}$ al NW de Ahuacatlán, Rzedowski 9292, 10879 (ENCB); Mpio. Xilitla, $3 \mathrm{~km}$ al SE de Ahuacatlán, Rzedowski 12358 (ENCB); VERACRUZ: Mpio. Huatusco, Elotepec, al N de Huatusco, Avendaño 367 (MEXU, XAL); Mpio. Yecuatla, Congregación La Paz de Enríquez, carretera Naolinco-Misantla, Calzada 5430 (ENCB, IEB, MEXU, XAL); Mpio. Huayacocotla, carretera al S de Huayacocotla, $17 \mathrm{~km}$ del borde con Hidalgo, Fay y Calzada 865 (XAL, TEX); Mpio. Atzalán, 9 km al NE de Atzalán $9 \mathrm{~km}$ al NE de Atzalán rumbo a Tlapacoyan, orillas del Río Alseseca, Lot 262 (XAL); Mpio. Los Reyes, colonia Bugambillea-Congocotepec, carretera Orizaba-Zongolica (km 32), Rincón 1396 (MEXU).

Especie dudosa. Viburnum parviflorum M.Martens \& Galeotti, Bull. Acad. Roy. Sci. Bruxelles 11(1): 243. 1844. TIPO: México. Oaxaca, Zacatepeque, H. G. Galeotti 7138 (Holotipo: BR). Ejemplar revisado: P03322824!

La descripción original y el ejemplar revisado, al parecer pertenecen a una muestra de $V$. tinoides Kunth, ampliamente cultivada como planta de ornato.

Es necesario, en estudios futuros, el análisis de los complejos de especies y las relaciones filogenéticas entre ellas, que incluyan técnicas moleculares y, de ser posible, genética de poblaciones, así como trabajo detallado de la anatomía, morfología del polen, flor, pirenos y semilla, que ayuden al mejor entendimiento de la diversidad del género.

\section{Agradecimientos}

A los curadores de los herbarios mencionados por las facilidades en la consulta de sus colecciones. A los revisores anónimos por sus valiosas observaciones. A Sven Landrein del herbario Kew por facilitar ilustraciones de tipos depositados en esta colección y la revisión del escrito. A Marcos B. Tejeda C. por su apoyo en la captura de datos, Juan A. Encina en la elaboración de los mapas y Gualberto J. Pérez por la elaboración del fenograma. A la Universidad Autónoma Agraria Antonio Narro que patrocinó el trabajo con recursos del proyecto 020302052100.

\section{Literatura citada}

Arreguín S.M.L. 2001. Caprifoliaceae. En: Calderón de Rzedowski G. y Rzedowski J. Eds. Flora Fanerogámica del Valle de México. 737-741, Instituto de Ecología A. C., Comisión Nacional para el Conocimiento y Uso de la Biodiversidad, Pátzcuaro.

Bentham G. 1840-41. Plantas Hartwegianas imprimis Mexicanas, adjectis nonnulis Grahamianisenumerat novasque describit. Londini, Zurich.

Dahlgren R.M.T. 1980. A revised system of classification of the Angiosperms. Botanical Journal of the Linnean Society 80:91124.

Donoghue M.J. 1982. Systematic studies in the genus Viburnum. Tesis doctoral. Universidad de Harvard. Cambridge. 1114 pp.

Donoghue M.J. 1983. A preliminary analysis of phylogenetic relationships in Viburnum (Caprofoliaceae s. 1.). Systematic Botany 8:45-58.

Donoghue M.J., Olmstead R.G., Smith J.F y Palmer J.D. 1992. Phylogenetic relationships of Dipsacales based on $r b c \mathrm{~L}$ sequences. Annals of the Missouri Botanical Garden 79:333-345.

Fritsch K. 1891. Caprifoliaceae. En: Engler A. y Prantl K. Eds. Die Natülichen Pflanzenfamilien, pp. 156-169, Verlag von Wilhelm Engelman, Leipzig.

Gibson D.N. 1973. Studies in American Plants, V. Phytologia 25:113-115.

Hara H. 1983. A Revision of the Caprifoliaceae of Japan with Reference to Allied Plants in other Districts and the Adoxaceae. Academia Scientific Book, Tokio.

Hemsley W.B. 1881. Biologia Centrali-Americana. Botany. Vol. II. R. H. Porter y Dulau and Co., Londres.

Linneo C. 1753. Species Plantarum. Laurentius Salvius. Estocolmo.

Lundell C.L. 1939a. Studies of Mexican and Central American plants. VII. Lloydia 2:73-108.

Lundell C.L. 1939b. Studies of Mexican and Central American plants VIII. Bulletin of the Torrey Botanical Club 66:583-604.

Lundell C.L. 1966. Studies of Tropical American plants III. Wrightia 3:161-172.

Martens M. y Galeotti H.G. 1844. Enumeratio synoptica plantarum phanerogamarum in regionibus Mexicanis ab Henrico Galeotti collectarum. Bulletins de l'académie Royale des Sciences et Belles-Lettres de Bruxelles 11:227-243.

Matuda E. 1956. Plantas nuevas e interesantes de México. Anales del Instituto de Biología de la Universidad Nacional de México 27:337-371.

Morton C.V. 1933. The Mexican and Central American species of Viburnum. Contributions from the United States National Herbarium 26:339-366.

Oersted A.S. 1861. Til belysning af slaegten Viburnum. Videnskabelige Meddelelser fra Dansk Naturhistorisk Forening i Kjobenhavn 13:267-305.

Rohlf F.J. 1998. NTSYSpc. Numerical Taxonomy and Multivariate 
Analysis System. Applied Biostatistics Inc., Nueva York.

Standley P.C. 1926. Caprifoliaceae. Trees and shrubs of Mexico. Contributions from the United States National Herbarium 23:1394-1400.

Thiers B. 2013. Index herbariorum: A global directory of public herbaria and associated staff. New York Botanical Garden's virtual herbarium.<http://sciweb.nybg.org/science2/IndexHerbariorum.asp>

Villarreal J.A. 2000. Viburnaceae. Flora del Bajío y de Regiones Adyacentes 86:1-9.

Recibido: 30 de junio de 2013

Aceptado: 2 de noviembre de 2013
Villarreal J.A. 2003. Viburnaceae. Flora de Veracruz 130:1-16. Villarreal J.A. 2012. Viburnaceae. Flora del Valle de TehuacánCuicatlán 97:1-8.

Villaseñor J.L., Ortiz, E. y Redonda-Martínez R. 2008. Catálogo de Autores de Plantas Vasculares de México. $2^{\mathrm{a}}$ ed. Instituto de Biología, Universidad Nacional Autónoma de México, Comisión Nacional para el Conocimiento y Uso de la Biodiversidad, México, D.F.

Winkworth R.C. y Donoghue M.J. 2005. Viburnum phylogeny based on combined molecular data: implications for taxonomy and biogeography. American Journal of Botany 92:653-666. 
Apéndice 1. Lista de nombres en el género Viburnum para México. Los nombres aceptados en este trabajo están en tipo de letra normal y los considerados como sinónimos en itálicas seguidos de un signo de igual (=).

V. affine $=\mathrm{V}$. rafinesquianum var. affine

$V$. amatenangenese $=V$. acutifolium var. lautum

V. australe $=\mathrm{V}$. rafinesquianum

V. acutifolium var. acutifolium

V. acutifolium var. blandum

V. acutifolium var. lautum

V. acutifolium var. microphyllum

V. acutifolium $=$ V. acutifolium var. acutifolium

V. blandum $=\mathrm{V}$. acutifolium var. blandum

V. blandum var. vulcanicum $=\mathrm{V}$. acutifolium var. blandum

V. caudatum

V. chiapense $=$ V. jucundum

V. ciliatum

V. cuneifolium $=V$. elatum

V. densum $=\mathrm{V}$. elatum

V. discolor

V. disjunctum

V. dispar $=$ V. acutifolium var. microphyllum

V. elatum

$V$. elatum var. cuneifolium $=\mathrm{V}$. elatum

$V$. ferruginosum $=V$. rufidulum

V. fuscum $=$ V. acutifolium var. acutifolium

$V$. guatemalense $=\mathrm{V}$. hartwegii

$\mathrm{V}$. hartwegii

V. hirsutum $=$ V. tiliifolium

V. jucundum

V. lautum $=$ V. acutifolium var. lautum

V. loeseneri

V. matudae $=V$. jucundum

V. MacDougalii $=$ V. membranaceum

V. membranaceum

V. microcarpum

V. microcarpum var. evanescens $=$ V. microcarpum

V. microphyllum $=\mathrm{V}$. acutifolium var. microphyllum

V. montanum $=\mathrm{V}$. acutifolium var. blandum

V. obtusatum

V. optatum $=$ V. acutifolium var. blandum

V. optatum var. vagum $=\mathrm{V}$. acutifolium var. blandum

V. parviflorum $=$ ? V. tinoides

$V$. pubescens var. affine $=V$. rafinesquianum

V. prunifolium $=\mathrm{V}$. rufidulum

V. rafinesquianum var. affine

V. rhombifolium $=$ V. tiliifolium

V. rufidulum

V. rufotomentosum $=\mathrm{V}$. rufidulum

V. siltepecanum $=\mathrm{V}$. acutifolium var. lautum

V. stellatum $=\mathrm{V}$. stenocalyx

V. stenocalyx

V. sulcatum

V. tacanense $=\mathrm{V}$. acutifolium var. lautum

V. tiliifolium 
Apéndice 2. Lista de caracteres y estados, empleados en el análisis de similitud.

1. Pubescencia en la planta: (1) pubescencia evidente, (0) glabra o casi glabra.

2. Tipo de pubescencia en la planta: (1) sólo de pelos estrellados, (0) mixta de pelos estrellados, simples o glandulares.

3. Forma de la hoja: (1) ovada, (0) elíptica a lanceolada.

4. Margen de la hoja: (1) dentado, (0) entero o casi entero.

5. Pubescencia del has: (1) notoriamente pubescente, (0) glabro o esparcidamente pubescente

6. Pubescencia del envés: (1) densamente pubescente, (0) restringida a los nervios

7. Nervios de la hoja: (1) 7-8, (0) 4-6.

8. Nervación hacia el margen: (1) continua, (0) anastomosada.

9. Dientes del margen en la hoja: (1) 4-7 mm de ancho y largo, (0) de menor tamaño.

10. Estípulas: (1) presentes, (0) ausentes.

11. Margen de la hoja: (1) ciliado, (0) no ciliado.

12. Textura de la hoja: (1) membranácea, (0) subcoriácea.

13. Color general de la hoja: (1) discolor, (0) concolor.

14. Puntos negros en envés de hoja e inflorescencia: (1) presentes, (0) ausentes.

15. Tamaño del pedúnculo: (1) menos de $1 \mathrm{~cm}$, (0) más de $1 \mathrm{~cm}$ de largo.

16. Inflorescencia: (1) pubescente, (0) glabra.

17. Tipo de pubescencia en pedicelos: (1) pelos estrellados, (0) pelos simples y/o glandulares

18. Tamaño de las cimas: (1) 1-2 cm largo, (0) $2.5-6 \mathrm{~cm}$ de largo.

19. Radios primarios en inflorescencia: (1) 6-7, (0) 4-5.

20. Ancho de la inflorescencia: (1) $5-8 \mathrm{~cm},(0) 2-4 \mathrm{~cm}$.

21. Cáliz: (1) pubescente, (0) glabro.

22. Corola: (1) pubescente, (0) glabra.

23. Estilo: (1) pubescente, (0) glabro.

24. Forma del fruto: (1) elipsoide, (0) esférico.

25. Largo del fruto: (1) 4.5-7 mm, (0) 3-4 mm de ancho

26. Color del fruto: (1) negro, (0) rojo.

27. Fruto: (1) aplanado, (0) no aplanado.

28. Fruto : (1) sulcado, (0) no sulcado.

29. Pireno con surco central: (1) presente, (0) ausente. 
